\title{
Group V Secretory Phospholipase A2 Regulates Endocytosis of Acetylated LDL by Transcriptional Activation of PGK1 in RAW264.7 Macrophage Cell Line
}

\author{
Daisuke Fujioka ${ }^{1}$, Yosuke Watanabe ${ }^{1}$, Takamitsu Nakamura1 ${ }^{1}$, Takashi Yokoyama², Keiji Miyazawa², \\ Makoto Murakami ${ }^{3,4}$ and Kiyotaka Kugiyama ${ }^{1,4}$
}

${ }^{1}$ Department of Internal Medicine II, University of Yamanashi, Faculty of Medicine, Chuo, Yamanashi, Japan

${ }^{2}$ Department of Biochemistry, University of Yamanashi, Faculty of Medicine, Chuo, Yamanashi, Japan

${ }^{3}$ Laboratory of Microenvironmental and Metabolic Health Science, Center for Disease Biology and Integrative Medicine, Graduate School of Medicine, University of Tokyo, Tokyo, Japan

${ }^{4}$ AMED-CREST, Japan Agency for Medical Research and Development, Tokyo, Japan

Aims: It was suggested that group V secretory phospholipase $A_{2}\left(s \mathrm{PLA}_{2}-\mathrm{V}\right)$ existed in the nucleus. This study examined whether nuclear sPLA2-V plays a role in endocytosis of acetylated low-density lipoprotein (AcLDL) in monocyte/macrophage-like cell line RAW264.7 cells.

Methods: RAW264.7 cells were transfected with shRNA vector targeting sPLA2-V (sPLA2-V-knockdown [KD] cells) or empty vector (sPLA2-V-wild-type [WT] cells). AcLDL endocytosis was assessed by incubation with ${ }^{125} \mathrm{I}-\mathrm{AcLDL}$ or AcLDL conjugated with $\mathrm{pHrodo}$. Actin polymerization was assessed by flow cytometry using Alexa Fluor 546-phalloidin.

Results: In immunofluorescence microscopic studies, sPLA2-V was detected in the nucleus. ChIP-Seq and ChIP-qPCR analyses showed binding of sPLA2-V to the promoter region of the phosphoglycerate kinase 1 (Pgk1) gene. In the promoter assay, sPLA2-V-KD cells had lower promoter activity of the Pgk1 gene than sPLA2-V-WT cells, and this decrease could be reversed by transfection with a vector encoding $5 \mathrm{PLA} 2-\mathrm{V}-\mathrm{H} 48 \mathrm{Q}$ that lacks enzymatic activity. Compared with sPLA2-V-WT cells, sPLA2-V-KD cells had decreased PGK1 protein expression, beclin 1 (Beclin1) phosphorylation at S30, and class III PI3-kinase activity that could also be restored by transfection with sPLA2-V-H48Q. sPLA2-V-KD cells had impaired actin polymerization and endocytosis, which was reversed by introduction of sPLA2-V-H48Q or PGK1 overexpression. In sPLA2-V-WT cells, siRNAmediated depletion of PGK1 suppressed Beclin1 phosphorylation and impaired actin polymerization and intracellular trafficking of $\mathrm{pHrodo-conjugated} \mathrm{AcLDL.}$

Conclusions: Nuclear sPLA2-V binds to the Pgk1 gene promoter region and increases its transcriptional activity. sPLA2-V regulates AcLDL endocytosis through PGK1-Beclin1 in a manner that is independent of its enzymatic activity in RAW264.7 cells.

Key words: Group V secretory phospholipase A2, Endocytosis, Phosphoglycerate kinase 1, Actin polymerization, Macrophage

\section{Introduction}

Phospholipase $\mathrm{A}_{2 s}\left(\mathrm{PLA}_{2}\right)$ participate in diverse biological events mainly through the generation of a variety of lipid mediators ${ }^{1)}$. Mammalian PLA2 enzymes are classified into three main categories based on their biochemical features and primary structures ${ }^{1)}$ : intracellular cytosolic PLA2 $\left(\mathrm{PLA}_{2}\right), \mathrm{Ca}^{2+}$

Address for correspondence: Kiyotaka Kugiyama, Department of Internal Medicine II, University of Yamanashi, Faculty of Medicine, 1110 Shimokato, Chuo, 4093898 JAPAN E-mail: kugiyama@yamanashi.ac.jp

Received: November 25, 2020 Accepted for publication: February 7, 2021

Copyright@2021 Japan Atherosclerosis Society

This article is distributed under the terms of the latest version of CC BY-NC-SA defined by the Creative Commons Attribution License. 
-independent $\mathrm{PLA}_{2}$ (iPLA ${ }_{2}$ ), and secretory PLA 2 (sPLA2). The sPLA2 class comprises 11 sPLA2s that are present in the secretory granule matrix, perinuclear region, or Golgi apparatus ${ }^{1,2)}$. After secretion, extracellular sPLA2s promote release of arachidonic acid and other fatty acids from plasma membrane phospholipids or non-cellular lipid components ${ }^{1,2)}$. Previous reports suggested that some sPLA2s including group $\mathrm{V}$ s $\mathrm{PLA}_{2}$ (sPLA2-V) localized within the nucleus ${ }^{3-5)}$. However, whether their nuclear localization has pathophysiological relevance is unclear. Notably, hydrolytic enzyme activity of sPLA2s requires $\mathrm{Ca}^{2+}$ concentrations in the millimolar range ${ }^{1)}$, and the $\mathrm{Ca}^{2+}$ concentration in both the nucleus and cytosol is at most a few $\mu \mathrm{M}^{6}$. Therefore, functional roles for $\mathrm{SPLA}_{2} \mathrm{~s}$ in the nucleus are likely mediated by non-enzymatic activities.

PLA2s have been reported to participate in innate immune functions through the regulation of phagocytosis ${ }^{7)}$. Macrophages contribute to the innate immune response by ingesting pathogens, internalizing them in phagosomes that later recruit lysosomal proteins to form phagolysosomes in which pathogens are killed ${ }^{8)}$. sPLA2-V was previously shown to regulate phagocytosis of microorganisms independently of its effects on eicosanoid generation in cultured murine macrophages ${ }^{9,10)}$. The precise mechanisms by which sPLA2s regulate phagocytosis are unclear. Endocytosis of modified low-density lipoproteins (LDL) through clathrin or non-clathrinmediated pathways ${ }^{11)}$ is thought to be central to the formation of foam cells, which are the basis for generation of atherosclerotic lesions. Whether ${ }_{s} P_{A} A_{2}-\mathrm{V}$ may also play a role in endocytosis of modified LDLs such as acetylated LDL (AcLDL) also remains to be determined.

While searching for the biological role of sPLA2-V in the nucleus of macrophages, we unexpectedly found that $s P L A_{2}-\mathrm{V}$ bound to the promoter region of phosphoglycerate kinase 1 (Pgk1) gene and promoted $P g k 1$ transcriptional activity in a non-enzymatical manner using the chromatin immunoprecipitation sequencing (ChIP-Seq) assay and the promotor assay. PGK1 is a key enzyme in the glycolytic pathway in which it catalyzes the reversible conversion of 1,3-biphosphoglycerate to 3-phosphoglycerate. PGK1 was recently shown to directly phosphorylate beclin $1(\text { Beclin } 1)^{12)}$, a protein that plays a key role in autophagy. Thus, PGK1 can act as a protein kinase to enhance autophagy, a novel role that is distinct from its glycolytic function ${ }^{13)}$. Beclin 1 is not only a key player in autophagy, but also serves non-autophagy functions including those involved in endocytic trafficking and phagocytosis ${ }^{14,15)}$.
Using the monocyte/macrophage-like cell line RAW264.7 cells, in this study we tested the hypothesis that $\mathrm{sPLA}_{2} \mathrm{~V}$ in the nucleus can regulate PGK1 expression that leads to enhanced endocytic activity of AcLDL.

\section{Materials and Methods}

\section{Materials}

FBS, RPMI 1640 medium, penicillin/ streptomycin solution, Alexa Fluor ${ }^{\mathrm{TM}} 488$ AcLDL,

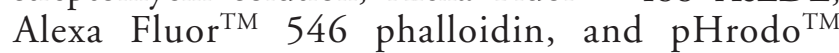
Indicator were purchased from Thermo Fisher Scientific (Waltham, MA, USA). AcLDL was from Alfa Diagnostic International (San Antonio, TX, USA). Sodium $\left[{ }^{125} \mathrm{I}\right]$-iodine (carrier-free, $3.7 \mathrm{GBq} / \mathrm{ml}$ ) was purchased from Perkin Elmer Japan (Yokohama, Kanagawa, Japan). Paraformaldehyde solution and saponin were from Sigma (Tokyo, Japan). EcoRI and BamHI restriction enzymes were obtained from New England Biolabs Japan (Tokyo, Japan). Rabbit monoclonal antibody against c-Src (clone no. 32G6; catalog. no. 2123), rabbit monoclonal antibody against phospho-c-Src at the active site (Tyr416; clone no. D49G4; cat. no. 6943), mouse and rabbit monoclonal antibody against Myc-tag (clone no. 9B11 and 71D10, cat. no. 2276 and 2278, respectively), rabbit monoclonal antibody against Beclin1 (clone no. D40C5; cat. no. 3495), rabbit polyclonal antibody against phospho-Beclin 1 at the active site (Ser30) (cat. no. 54101), rabbit monoclonal antibodies against Rab5 (clone no. C8B1; cat. no. 3547) and Rab7 (clone no. D95F2; cat. no. 9367), rabbit polyclonal antibody against Lamin (cat. no. 2032), and rabbit monoclonal antibody against $\beta$-tubulin (clone no. 9F3; cat. no. 2128) were purchased from Cell Signaling Technology Japan (Tokyo, Japan). Rabbit polyclonal antibody to $s \mathrm{PLA}_{2}-\mathrm{V}$ for immunofluorescence study was purchased from Abcam Japan, Tokyo (cat. no. ab23709). Mouse monoclonal antibody against GAPDH (clone no. 3E12; cat. no. bsm-0978M) was from Bioss (Woburn, MA, USA). Rabbit polyclonal antibody against PGK1 (cat. no. LS-C482333) was obtained from LSBio (Seattle, WA, USA). Rat monoclonal antibody against Scavenger receptor class A member 1 (SR-A1) conjugated with FITC (clone no. 268318; cat. no. FAB1797F) was purchased from $\mathrm{R}$ and $\mathrm{D}$ systems (Minneapolis, MN, USA). Other chemicals were purchased from Sigma unless otherwise indicated.

\section{Cell Culture}

The RAW264.7 cell line, which is a monocyte/ macrophage-like cell line derived from BALB/C mice, 
was obtained from the American Type Culture Collection (Manassas, VA, USA; ATCC no. TIB-71). The cells were cultured in RPMI 1640 medium containing 10\% FBS, 100 units/mL penicillin, and $100 \mu \mathrm{g} / \mathrm{mL}$ streptomycin in an atmosphere of 5\% $\mathrm{CO}_{2}$ at $37^{\circ} \mathrm{C}$. Cells were passaged at $90 \%$ confluency and used for experiments within passage number 15 .

Details regarding the generation and characterization of $s \mathrm{PLA}_{2}-\mathrm{V}$ knockout $(\mathrm{KO})$ mice with a C57BL/6J background (systemically deficient in $\left.{ }_{s} P_{A_{2}}-\mathrm{V}\right)$ are described in our previous report ${ }^{16}$. sPLA2-V KO male mice (20-25 wks-old) were used in the present study. Littermates of the sPLA2-V wildtype (WT) males served as a WT group. Peritoneal macrophages were isolated from sPLA2-V KO and WT mice by flushing the peritoneal cavities of mice with $5 \mathrm{~mL}$ ice-cold RPMI 1640 medium. The isolated peritoneal macrophages were washed and resuspended with RPMI 1640 medium containing 10\% FBS, 100 units $/ \mathrm{mL}$ penicillin, and $100 \mu \mathrm{g} / \mathrm{mL}$ streptomycin, and then plated on 24- or 48-well tissue culture plates. The cells were incubated overnight at $37^{\circ} \mathrm{C}$ with $5 \%$ $\mathrm{CO}_{2}$. Nonadherent cells were removed by washing three times with PBS. Peritoneal macrophages isolated as adherent Mac-2-positive cells were obtained at $>$ 95\% purity. The experimental protocol was approved by the University of Yamanashi Animal Care and Use Committee (approval reference no. A28-37), and procedures were carried out in accordance with the Guide for the Care and Use of Laboratory Animals published by the U.S. National Institutes of Health (NIH Publication, 8th Edition, 2011).

Stable Knockdown (KD) of sPLA2-V with Short Hairpin RNA (shRNA) in RAW264.7 Cells and Transfection of Small Interfering RNAs (siRNAs)

Predesigned short hairpin RNA (shRNA) specifically targeting sPLA2-V was cloned into the pLKO.1 vector (Sigma). The shRNA sequence was: 5'-CCGGGCTAGAACTCAAGTCCATGATCTCG AGATCATGGACTTGAGTTCTAGCTTTTTG-3' (cat. no. TRCN0000222633). The negative control shRNA (cat. no. SHC002V) sequence was: 5'-CCGG CAACAAGATGAAGAGCACCAACTCGAGTTGG TGCTCTTCATCTTGTTGTTTTT-3’. Stable knockdown (KD) of sPLA2-V in RAW264.7 cells was established as previously described ${ }^{17)}$. Briefly, cells cultured on a 24-well plate were transfected with 0.8 $\mu \mathrm{g}$ of the shRNA targeting sPLA2-V using FuGENE HD transfection reagent (Promega Japan, Tokyo, Japan) according to the manufacturer's instructions. After selection of transfected cells with puromycin (final concentration $3 \mu \mathrm{g} / \mathrm{mL}$ ), some monoclonal cell populations were isolated from the stable cell pool by limiting dilution. Some cells from each clone were collected for RT-PCR screening of sPLA2-V mRNA knockdown. Meanwhile, the same procedure was used to isolate stable controls (RAW264.7 cells with WT $\left.{ }_{s} \mathrm{PLA}_{2}-\mathrm{V}\right)$ from cells transfected with the negative control shRNA vector. Efficiency of gene knockdown was confirmed by quantitative real-time (RT) PCR and immunoblotting.

Predesigned small interfering RNAs (siRNAs) specific for mouse PGK1, Beclin1, vacuolar protein sorting 34 (VPS34), and sPLAz-IID, -IIE, and XIIA were obtained from Sigma. The sense strand sequences are listed in Supplementary Table 1. The sequence of negative control siRNA (cat. no. SIC002) was not provided. RAW264.7 cells were transiently transfected with $30 \mathrm{nM}$ siRNAs using Lipofectamine RNAiMAX reagent (Thermo Fishier Scientific), and the cells were used for experiments within $48 \mathrm{hr}$ after the transfection. The efficacy of the siRNA-mediated suppression was confirmed by RT-PCR and western blot.

Transfection of shRNA, siRNAs, or any cDNA constructs was not performed using peritoneal macrophages due to the low transfection efficiency of primary macrophages with DNA constructs ${ }^{18)}$.

Generation and Transfection of cDNA Constructs Encoding Mouse sPLA2-V, sPLA2-V- H48Q, Myctagged sPLA2-V, Myc-tagged sPLA2-V-H48Q, GFPtagged sPLA2-V, and Mouse PGK1 and c-Src

pCMV6-Entry vector encoding a C-terminal Myc-tagged mouse sPLA2-V (accession no. NM_011110.4) was purchased from OriGene Technologies (Rockville, MD, USA). At first, we generated cDNA encoding a mutant of sPLA2-V to transfect into RAW264.7 cells having shRNAmediated knockdown of $s_{P L A}-V$. Site-specific mutations were introduced using mismatched primer PCR with $P f u$ DNA polymerase and $D p n$ I restriction enzyme and a plasmid vector encoding a C-terminal Myc-tagged mouse sPLA2-V as a template according to the manufacturer's instructions (Agilent Technologies, Santa Clara, CA, USA). The primers for the mutations of nucleotides without any changes of amino acids are described in Supplementary Table 1. Then, $\mathrm{cDNA}$ construct of mouse sPLA2-V lacking the Myc-tag was generated by the similar way using the respective primers (Supplementary Table 1). cDNA constructs of mouse sPLA2-V encoding the activityablated mutant $\mathrm{H} 48 \mathrm{Q}^{19)}$, with and without the Myctag, were also produced with a site-specific mutation method and a pCMV6-Entry vector carrying mouse sPLA2-V cDNA with or without Myc-tag as a template. The primers for generation of the $\mathrm{H} 48 \mathrm{Q}$ 
mutant are described in Supplementary Table 1. A GFP-tagged mouse sPLA2-V expression vector was generated by subcloning mouse sPLA2-V cDNA into the pAcGFP1-N1 vector (Takara Bio, Kusatsu, Shiga, Japan) using the EcoRI and AgeI restriction sites. The pAcGFP1-N1-empty vector was used as a GFPexpression control vector. A mouse PGK1 expression vector (accession no. NM_008828) was purchased from Origene Technologies. A mouse c-Src expression vector (accession no. NM_001025395) was purchased from Origene Technologies. RAW264.7 cells were transiently transfected with each of these expression vectors using FuGENE HD transfection reagent (Promega Japan), and the cells were used within two days of transfection. Expression efficacy was analyzed by RT-PCR and immunoblotting.

\section{ChIP-Seq and Quantitative ChIP-PCR in RAW264.7 Cells}

ChIP-Seq was performed using truChIP Chromatin Shearing Kit (Covaris, Woburn, MA, USA) and iDeal ChIP-seq kit for Transcription Factors (Diagenode, Seraing, Belgium) according to the manufacturer's instructions and our previous report ${ }^{20)}$. Since we previously had technical problems due to unavailability of antibodies that specifically detect sPLA2-V in tissues by immunoblotting ${ }^{16)}$, we used a monoclonal antibody against the Myc-tag and analyzed sPLA2-V KD RAW264.7 cells with re-constitutive expression of Myc-tagged sPLA2-V or Myc-tagged sPLA2-V-H48Q as well as sPLA2-V KD RAW264.7 cells transfected with empty vector. Briefly, RAW264.7 cells $\left(4 \times 10^{6}\right.$ cells $/ 10 \mathrm{~cm}$ dish $)$ were crosslinked in $1 \%$ formaldehyde for $5 \mathrm{~min}$ at room temperature. The reaction was quenched by addition of glycine to a final concentration of $0.125 \mathrm{M}$ and incubation for $5 \mathrm{~min}$ at room temperature. After quenching, the cells were washed and collected in PBS before incubation with lysis buffer to prepare the nuclei. The nuclei were pelleted and resuspended with shearing buffer for sonication of chromatin using a Covaris M220 Focused-ultrasonicator (Covaris, Woburn, MA, USA) that sheared the chromatin into 200-700 bp fragments (75 W peak power, 10\% duty factor, 200 cycles/burst, for $20 \mathrm{~s}$ ). The lysate was kept cold at all times during sonication. A portion of the chromatin lysate was set aside as an input control. The remainder of the chromatin lysate was used for the ChIP experiment using mouse monoclonal antibody against Myc-tag (1:100 dilution; clone no. 9B11, catalog no. 2276, Cell Signaling Technology Japan, Tokyo, Japan). Normal mouse IgG (cat. no. 015-000003, Jackson ImmunoResearch Laboratories, West Grove, PA, USA) was used as a negative control.
Chromatin-antibody complexes were pulled down using protein A-coated magnetic beads. The isolated DNA was purified and Illumina sequencing libraries were prepared using an Illumina TruSeq DNA Sample prep Kit (Illumina, San Diego, CA, USA). Libraries were PCR amplified for 18 cycles. Several libraries were pooled on one NovaSeq6000 lane and sequenced. Fastq files were first trimmed using Trimmomatic to remove poor quality reads and adapters. Reads from the trimmed Fastq files were aligned to the reference mouse genome ( $\mathrm{mm} 10)$ using Bowtie to produce sam files. Duplicate reads were then removed using Picard tools. ChIP-Seq peaks were called using the MACS2 algorithm, then annotated using ChIPseeker.

Data obtained after ChIP-Seq was validated by ChIP-quantitative PCR (qPCR). Immunoprecipitated DNA samples using mouse anti-Myc-tag monoclonal antibody and control mouse IgG were amplified and quantitated using Pgk1 primers (Supplementary Table 1). Amplification reactions $(20 \mu \mathrm{L}$ total volume $)$ contained $1 \mu \mathrm{L}$ DNA (Input/ChIP), $500 \mathrm{nM}$ of the respective primers and SYBR Green Master Mix (Toyobo, Osaka, Japan). Data were calculated by normalizing relative to input sample (percentage of input).

Assay of Pgk1 Gene Promoter Activity in RAW264.7 Cells

We used secreted luciferase from Cypridina. The Pgk1 promoter (-648 to -50$)$ was amplified from mouse genomic DNA by PCR and cloned into the Cypridina luciferase reporter plasmid pMCSCypridina Luc (Thermo Fisher Scientific) at the Xho I and $B a m H I$ restriction sites. sPLA $-\mathrm{V}-\mathrm{WT}$ and ${ }_{s} P_{2} A_{2}-\mathrm{V} \mathrm{KD}$ cells as well as sPLA $2-\mathrm{V} \mathrm{KD}$ cells expressing sPLA2-V-H48Q were transfected with Cypridina luciferase reporter vector using FuGENE HD Transfection Reagent (Promega) according to the manufacturer's instructions. Renilla luciferase expression vector (pTK-Green Renilla Luc, Thermo Fisher Scientific) was co-transfected to serve as an internal control. At $24 \mathrm{hr}$ post transfection, the culture medium and the cells were harvested. Cypridina luciferase activity in the harvested culture medium was measured using a SpectraMax L luminometer (Molecular Devices, San Jose, CA, USA) and a Pierce Cypridina Luciferase Glow Assay Kit (Thermo Fisher Scientific). Renilla luciferase activity in cellular lysates was measured on the luminometer using coelenterazine as a substrate. Cypridina luciferase activity was normalized to Renilla luciferase activity. Data are represented as fold-induction by normalizing the luciferase activity of the tested sample to that of the corresponding control sample. 
Assay of Class III Phosphatidylinositol 3-kinase (PI3-kinase) Activity in RAW264.7 Cells

RAW264.7 cells were incubated with $20 \mu \mathrm{g} / \mathrm{mL}$ AcLDL or PBS as a vehicle for $2 \mathrm{hr}$, washed with cold PBS, and lysed with lysis buffer (Sigma). Vacuolar protein sorting 34 (VPS34) protein complexes in the cell lysates were immunoprecipitated using rabbit antiVPS34 monoclonal antibody (clone no. D9A5; cat no. 4263, Cell Signaling Technology Japan) or IgG as a control (cat. no. 011-000-003, Jackson Immuno Research Laboratories). VPS34 protein complexes were pulled down with protein $G$ magnetic beads and washed with $\mathrm{PBS} / 0.02 \%$ Tween 20 . The enzyme activity of the VPS34 protein complex was determined using Class III PI3-Kinase Kit (K-3000; Echelon BioSciences, Salt Lake City, UT, USA) according to the manufacturer's instructions. Briefly, $12.5 \mu \mathrm{L}$ kinase reaction buffer $(20 \mathrm{mM}$ Tris at $\mathrm{pH} 8.0,200 \mathrm{mM} \mathrm{NaCl}$, $2 \mathrm{mM}$ EDTA, $20 \mathrm{mM} \mathrm{MnCl} 2,100 \mu \mathrm{M}$ ATP) was added to the immune complex bound to beads and incubated at $30^{\circ} \mathrm{C}$ for $3 \mathrm{hr}$. The reaction was terminated by adding $5 \mu \mathrm{L} 100 \mathrm{mM}$ EDTA. The quenched reaction mixture and phosphatidylinositol 3-phosphate $(\mathrm{PI}[3] \mathrm{P})$ detector protein (provided with the kit) were mixed in a $\mathrm{PI}(3) \mathrm{P}$-coated microplate for competitive binding to the $\mathrm{PI}(3) \mathrm{P}$ detector protein. The amount of $\mathrm{PI}(3) \mathrm{P}$ detector protein bound to the plate was determined using colorimetric detection of absorbance at $450 \mathrm{~nm}$. The concentration of $\mathrm{PI}(3) \mathrm{P}$ remaining in the reaction mixture was calculated based on the amount of PI(3)P detector protein bound to the plate.

Binding, Internalization, and Degradation Assays for AcLDL in RAW264.7 Cells and Mouse Peritoneal Macrophages

AcLDL was labeled with $\mathrm{Na}^{125} \mathrm{I}$ (Parkin Elmer Japan, Yokohama, Japan) in pre-coated iodination tubes (Thermo Fisher Scientific) to yield a specific activity of $100-150 \mathrm{kBq} / \mu \mathrm{g}$ AcLDL protein. For the binding study, cultures of RAW264.7 cells or peritoneal macrophages on 24-well culture plates were incubated for $2 \mathrm{hr}$ at $4^{\circ} \mathrm{C}$ with the indicated concentrations of ${ }^{125}$ I-labeled AcLDL in RPMI 1640 medium containing $0.1 \% \mathrm{BSA}$ in the absence or presence of 50-fold excess unlabeled AcLDL. After the reaction was stopped by rapid removal of the medium, the cells were washed three times with ice-cold PBS, and then the cell-associated radioactivity was counted after solubilization with $1 \mathrm{~N} \mathrm{NaOH}$. The specific binding is defined as the difference between binding in the presence and absence of unlabeled AcLDL. To assess AcLDL internalization and degradation, cultures of RAW264.7 cells or peritoneal macrophages on 24-well culture plates were incubated for $2 \mathrm{hr}$ at $4^{\circ} \mathrm{C}$ with $20 \mu \mathrm{g} / \mathrm{mL}{ }^{125}$ I-labeled AcLDL in RPMI 1640 medium containing $0.1 \% \mathrm{BSA}$ in the absence or presence of 50-fold excess unlabeled AcLDL. The supernatants were removed, washed with ice-cold PBS, then further incubated in RPMI 1640 medium containing $0.1 \%$ BSA for the indicated times at $37^{\circ} \mathrm{C}$. At the end of the incubation at $37^{\circ} \mathrm{C}$, the culture medium was collected and kept on ice for the later measurement of degradation. The cells were treated with an acidic buffer $(50 \mathrm{mM}$ glycine, $0.1 \mathrm{M} \mathrm{NaCl}$, $\mathrm{pH} 3.0$ ) for $10 \mathrm{~min}$ at $4^{\circ} \mathrm{C}$ to remove AcLDL associated with the cell surface. After washing with PBS, the internalized radioactivity was measured with a gamma counter after solubilization of the cells with $1 \mathrm{~N} \mathrm{NaOH}$. The specific internalization is defined as the difference between the internalized radioactivity in the presence and absence of the unlabeled AcLDL. To measure AcLDL degradation, the collected culture medium as described before was precipitated with $10 \%$ trichloroacetic acid (TCA). The TCA-soluble radioactivity was measured with a gamma counter. The specific degradation is defined as the difference between the TCA-soluble radioactivity in the presence and absence of unlabeled AcLDL.

To evaluate whether the translocation of AcLDL from the early endosome compartment to the late endosome/lysosome was impaired in sPLA2-V KD cells, a pulse-chase experiment was performed. Briefly, cells were incubated for the indicated time for up to 1 hr with ${ }^{125} \mathrm{I}$-AcLDL at $18^{\circ} \mathrm{C}$ with or without 50 -fold excess of unlabeled AcLDL. At this temperature, AcLDL degradation is inhibited by suppression of endosome-lysosome fusion ${ }^{21)}$ and internalized AcLDL accumulates in the early-endosomal compartments. After the cells were washed with PBS to remove unbound AcLDL, a portion of the cultured cells was harvested and the cell internalized radioactivity was measured as described above. The remaining cells were further incubated for the indicated time up to $1 \mathrm{hr}$ at $37^{\circ} \mathrm{C}$ at which time point the culture medium was collected and precipitated with 10\% TCA. The TCAsoluble radioactivity as AcLDL degradation was measured as described above. The degradation efficiency was expressed as the percentage of the TCAsoluble radioactivity relative to the specific cell internalized radioactivity after $1 \mathrm{hr}$ incubation at $18^{\circ} \mathrm{C}$ $(=100 \%)$. The degradation efficiency reflects the rate of translocation of the internalized AcLDL to the late endosome/lysosome compartment.

Detection of Rab5 and Rab7 Recruitment to Endosomes Containing AcLDL and Translocation of Internalized AcLDL to Lysosomes

Fluorescein-labeled AcLDL (Thermo Fisher 
Scientific) was incubated with RAW264.7 cells at $4{ }^{\circ} \mathrm{C}$ for $2 \mathrm{hr}$ in 24-well plates with cover slips, then removed, and the cells were washed with ice-cold PBS twice and further incubated at $37^{\circ} \mathrm{C}$ for the indicated times in RPMI 1640 medium containing $0.1 \%$ BSA. Then, cells were fixed with $4 \%$ paraformaldehyde for $15 \mathrm{~min}$ at room temperature. The fixed cells were permeabilized with $0.025 \%$ saponin and incubated with a primary antibody against Rab5 or Rab7 followed by Alexa Fluor 546-coujugated anti-rabbit IgG (cat. no. A11010, Thermo Fisher Scientific) for confocal microscopy.

Translocation of internalized AcLDL to lysosomes was detected using AcLDL conjugated with pHrodo (Thermo Fisher Scientific), a $\mathrm{pH}$ indicator that emits green fluorescence under acidic conditions such as those found in lysosomes. RAW264.7 cells were incubated with $20 \mu \mathrm{g} / \mathrm{mL}$ AcLDL conjugated with pHrodo at $37^{\circ} \mathrm{C}$ for the indicated time, and confocal microscopy and flow cytometry were carried out. For flow cytometry, data were collected as histograms representing the distribution of cell fluorescence intensities, and geometrical means of each histogram were used to assess the degree of translocation of internalized AcLDL to lysosomes. For each sample, 50,000 cells were analyzed by flow cytometry.

The level of lysosomal acidification was examined using LysoTracker Red (Thermo Fisher Scientific) that emits red fluorescence after accumulation in acidic compartments such as lysosomes. RAW264.7 cells at baseline were incubated with $50 \mathrm{nM}$ LysoTracker Red at $37^{\circ} \mathrm{C}$ for $30 \mathrm{~min}$ in RPMI medium and used for confocal microscopy. The area of red fluorescence in each cell was measured using ImageJ and expressed as the percentage of area showing red fluorescence relative to the cell-surface area, and averaged over at least 20 cells.

\section{Flow Cytometric Analysis}

The magnitude of actin polymerization was assessed by measuring the relative content of F-actin in cells by flow cytometry ${ }^{22)}$. At the indicated time after addition of AcLDL, cells were fixed with $4 \%$ paraformaldehyde and permeabilized with 0.025\% saponin. Then, the fixed and permeabilized cells were incubated with Alexa Fluor 546-phalloidin (Thermo Fisher Scientific) for $30 \mathrm{~min}$ on ice. A portion of the cells was analyzed by confocal microscopy. The remaining cells were washed, scraped from the plate, and analyzed by flow cytometry using a FACSCalibur instrument (FACSCalibur, BD Biosciences, San Jose, CA, USA). To assess the magnitude of cell-surface expression of Scavenger receptor class A member 1 (SR-A1), a main AcLDL receptor, RAW264.7 cells were incubated with FITC-conjugated anti-SR-A1 monoclonal antibody (1:100 dilution, clone no. 268318; cat. no. FAB1797F, R and D systems) and analyzed by flow cytometry.

Data are presented as histograms showing the distribution of cell fluorescence intensities, and geometrical means of each histogram were used to assess actin polymerization or SR-A1 expression. For each sample, 50,000 cells were analyzed by flow cytometry.

\section{Immunofluorescence Study}

When nuclear localization of sPLA2-V and Myc${ }_{s} P_{L A}-V$ was examined, cells were treated for $10 \mathrm{~min}$ with $20 \mu \mathrm{g} / \mathrm{mL}$ of AcLDL or PBS as a vehicle in 24-well plates with cover slips, washed with PBS, fixed with $2 \%$ paraformaldehyde, and permeabilized with $0.1 \%$ Triton X-100. The fixed cells were incubated with anti-sPLA2-V polyclonal antibody (1:100 dilution, cat. no. ab23709, Abcam) or anti-Myc-tag monoclonal antibody (1:500 dilution, clone no. 71D10, cat. no. 2278, Cell Signaling Technology) followed by incubation with Alexa Fluor 488-conjugated anti-rabbit IgG (cat. no. A11008, Thermo Fisher Scientific). Nuclei were stained with $4^{\prime}, 6$-diamidino-2-phenylindole (DAPI). Immunofluorescence study for the intracellular presence of Rab5 and Rab7 was described before.

\section{Confocal Microscopy in Cells}

Images were acquired with an Olympus FluoView 1000 confocal microscope system (Olympus, Tokyo, Japan) and processed using FV10ASW software version 1.0 (Olympus) using appropriate wavelength of excitation laser and bandpass filter for emitted light according to the manufacture's instruction. Images of the cells were taken consecutively with $1 \mu \mathrm{m}$ intervals from the bottom edge to the top edge of the nucleus. The number of images captured was approximately 5-7 per cell. Among them, the single image that represents the most center of the nucleus was selected. Thus, the images of the nucleus do not include cytosolic staining above and below the nucleus. Images of sPLA2-V KD RAW264.7 cells with expression of GFP alone or GFP-sPLA2-V were taken after fixation with $4 \%$ paraformaldehyde. When pHrodo indicator or LysoTracker Red was used, cells were incubated with pHrodo-conjugated AcLDL or Lysotracker Red, and unfixed cells containing pHrodo or LysoTracker Red were viewed using the same confocal microscopy system.

\section{Immunostaining of Isolated Nuclei}

Nuclei were isolated by cell lysis buffer using 
Nuclei EZ Prep Nuclei Isolation Kit (Nuc-101, Sigma) according to the manufacture's instruction. Cells were lysed by ice-cold Nuclei EZ Lysis Buffer. After centrifugation at $500 \times \mathrm{g}$ for $5 \mathrm{~min}$ at $4{ }^{\circ} \mathrm{C}$, the nuclei pellet was washed with the same lysis buffer, followed by the centrifugation for $5 \mathrm{~min}$ at $4{ }^{\circ} \mathrm{C}$ to remove remaining cytoplasmic contents. The final nuclear pellet was resuspended in Nuclei EZ Storage Buffer, being seeded on the silane-coated slides by cytospin centrifugation, fixed with $2 \%$ paraformaldehyde, and permeabilized with $0.1 \%$ Triton X-100. The fixed nuclei were served to immunofluorescence and confocal microscopic studies with similar procedure performed with whole cells, as described before.

\section{Western Blotting Analysis}

Protein $(15 \mu \mathrm{g})$ from extracts of cultured cells was applied to a 4-20\% SDS-PAGE gel (Bio-Rad Laboratories, Tokyo, Japan) under reducing conditions and subsequently transferred to a polyvinylidene difluoride membrane. The membrane was treated with blocking buffer at room temperature for $1 \mathrm{hr}$ and then incubated at $4{ }^{\circ} \mathrm{C}$ overnight with primary antibody. After washing, the membrane was incubated at room temperature for $1 \mathrm{~h}$ with $\mathrm{HRP}$-conjugated goat anti-mouse or anti-rabbit $\operatorname{IgG}$ as the secondary antibody (dilution 1:10,000; cat. no. 115-035-146 and 111-035-003, respectively, Jackson ImmunoResearch Laboratories). Protein bands were visualized with Amersham ECL prime western blotting detection reagents (Cytiva, Tokyo, Japan). Samples were normalized relative to the intensity of the GAPDH or $\beta$-tubulin bands.

\section{Real-time Quantitative PCR (RT-PCR)}

The efficiency of the transfection of vectors encoding $s_{\mathrm{PLA}}-\mathrm{V}$ and $\mathrm{sPLA}_{2}-\mathrm{V}-\mathrm{H} 48 \mathrm{Q}$ with or without Myc-tag, and GFP-tagged sPLA2-V as well as the efficiency of knockdown of $s P L A_{2}-\mathrm{V}$ were evaluated by RT-PCR. Total RNA was isolated from cell homogenates with TRI Reagent (Sigma), reversetranscribed into cDNA (ReverTra Ace qPCR RT Kit; Toyobo, Osaka, Japan), and assayed by qPCR using a 7500 Real Time PCR System (Thermo Fisher Scientific) and SYBR Green/ROX Master Mix (Toyobo). The ratio of each mRNA relative to the GAPDH mRNA was calculated using the $\Delta \Delta C_{\mathrm{T}}$ method. Primer pairs for respective genes are listed in Supplementary Table 1.

\section{Statistics}

All data are expressed as means \pm SE. Statistical analysis was performed using GraphPad Prism software (version 5.01, GraphPad, La Jolla, CA). Differences between two groups were assessed by using an unpaired $t$-test. Analysis of more than two groups was carried out either by one-way ANOVA or twoway ANOVA followed by a Scheffe test for post hoc comparison of group means. $P<0.05$ was considered significant.

\section{Results}

Nuclear Localization of sPLA2-V and Myc-sPLA2-V in RAW264.7 Cells and Peritoneal Macrophages

Fluorescence microscopy using an antibody against $\mathrm{SPLA}_{2}-\mathrm{V}$ showed that the immunoreactivity of sPLA2-V was detected in the nucleus as well as cytoplasmic area of $\mathrm{sPLA}_{2} \mathrm{~V}$ knockdown (KD) RAW264.7 cells with re-constitutive expression of sPLA2-V (Fig. 1A). The immunoreactivity of MycsPLA2-V was also detected in the nucleus as well as cytoplasmic area of sPLA2-V KD RAW264.7 cells with re-constitutive expression of Myc-sPLA2-V using an anti-Myc-tag antibody (Fig.1B). The immunoreactivity was not detected in $\mathrm{sLA}_{2}-\mathrm{V} \mathrm{KD}$ RAW264.7 cells transfected with empty vector (lower panels in Figs. 1A and 1B). In addition, endogenous sPLA $2-\mathrm{V}$ was detected using an antibody against sPLA2-V in the nucleus as well as cytoplasmic area of the peritoneal macrophages from sPLA2-V WT mice, but the immunoreactivity was not detected in cells from sPLA2-V KO mice (Fig.1C). In these immunofluorescence microscopies, extent of the immunoreactivity of sPLA2-V or Myc-sPLA2-V in the nucleus appeared to be lower than that in the cytoplasmic area. In Fig. 1D, immunofluorescence study using anti-sPLA2-V antibody shows cell images taken consecutively with $1 \mu \mathrm{m}$ intervals from the bottom edge to the top edge of the nucleus in peritoneal macrophages from sPLA2-V WT mice. The images in Fig. 1D show that the immunoreactivity of endogenous sPLA2-V existed within the nucleus as well as in the cytoplasmic area of the peritoneal macrophages. GFP-tagged sPLA2-V protein was detectable in the nuclear region as well as in the cytoplasmic region (Fig.2A). When the cells were stimulated with AcLDL, the extent of expression of ${ }_{s} P_{A_{2}}-\mathrm{V}, \mathrm{Myc}_{\mathrm{c}} \mathrm{PLA} \mathrm{A}_{2}-\mathrm{V}$, and GFP- sPLA2-V in the nucleus showed no remarkable changes (Figs. 1A, 1B, $1 \mathrm{C}$, and 2A). In agreement with these immunofluorescence studies using whole cells, immunoreactivity of sPLA2-V or Myc-sPLA2-V was detected in the isolated nuclei from sPLA2-V KD RAW264.7 cells with re-constitutive expression of each of them and from peritoneal macrophages of sPLA $2-V$ WT mice (Supplementary Fig. 1). Since we 

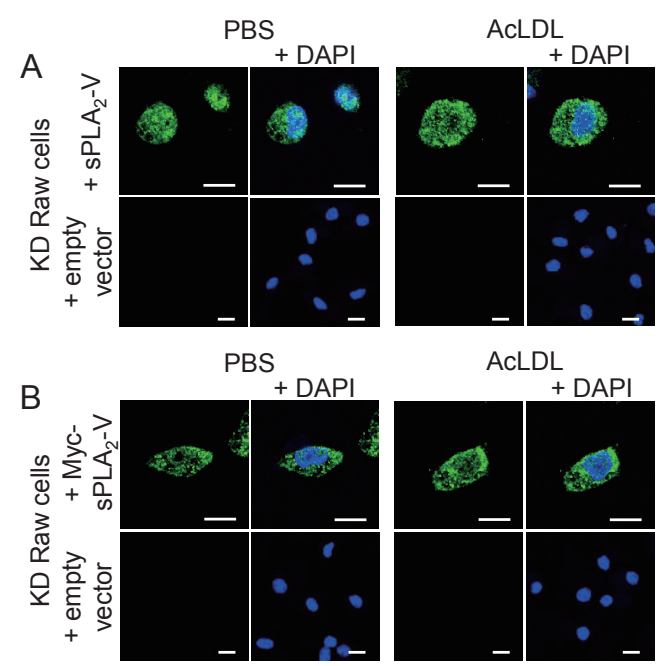

AcLDL
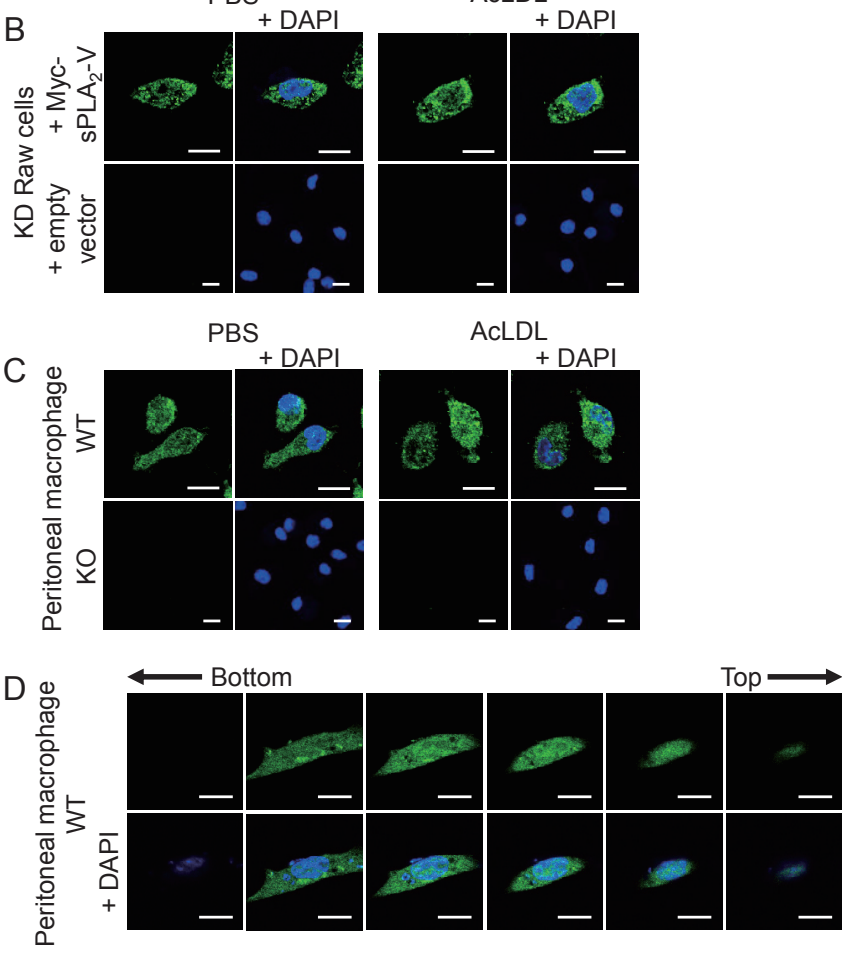

Fig. 1. Immunofluorescence microscopic studies using antisPLA2-V antibody or anti-Myc-tag antibody for nuclear localization of sPLA2-V

Scale bars were $10 \mu \mathrm{m}$. Nuclei were visualized with 4',6-diamidino-2-phenylindole (DAPI) (blue). A and B, Immunoreactivity (green) of ${ }_{s P L A}-\mathrm{V}$ and $\mathrm{Myc}_{-} \mathrm{SPLA}-\mathrm{V}$ was detected in the nucleus as well as in the cytoplasmic area in sPLA2-V KD RAW264.7 cells with re-constitutive expression of sPLA2-V or Myc-sPLA2-V, respectively, 10 min after addition of 20 $\mu \mathrm{g} / \mathrm{mL}$ of AcLDL or PBS as a vehicle. Their immunoreactivities in the nucleus appeared to be lower than those in the cytoplasmic area. The immunoreactivity was not detected in $s^{P L A} 2-\mathrm{VD}$ RAW264.7 cells transfected with empty vector (lower panels). C, Immunoreactivity of endogenous $s \mathrm{PLA}_{2}-\mathrm{V}$ was detected in the nucleus as well as in the cytoplasmic area of primary peritoneal macrophages from $s \mathrm{PLA}_{2}-\mathrm{V}$ wild-type (WT) mice but not from sPLA $2-V$ knockout $(\mathrm{KO})$ mice. $\mathrm{D}$, In peritoneal macrophages from sPLA2-V WT mice, confocal microscopic images of the cells were taken consecutively at $1 \mu \mathrm{m}$ intervals from the bottom edge to the top edge of the nucleus. Immunoreactivity of endogenous sPLA2-V was detected within nucleus as well as in the cytoplasmic area.
A
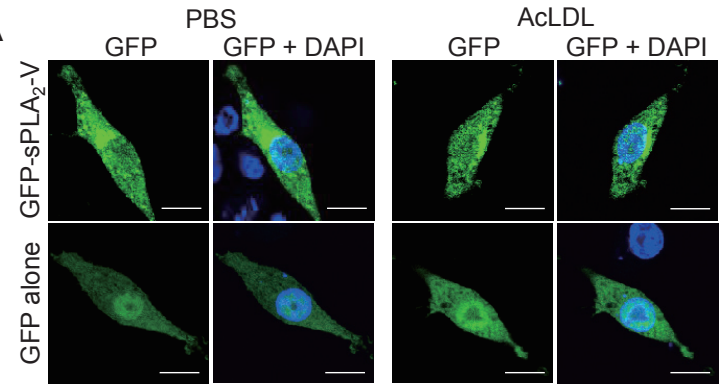

B
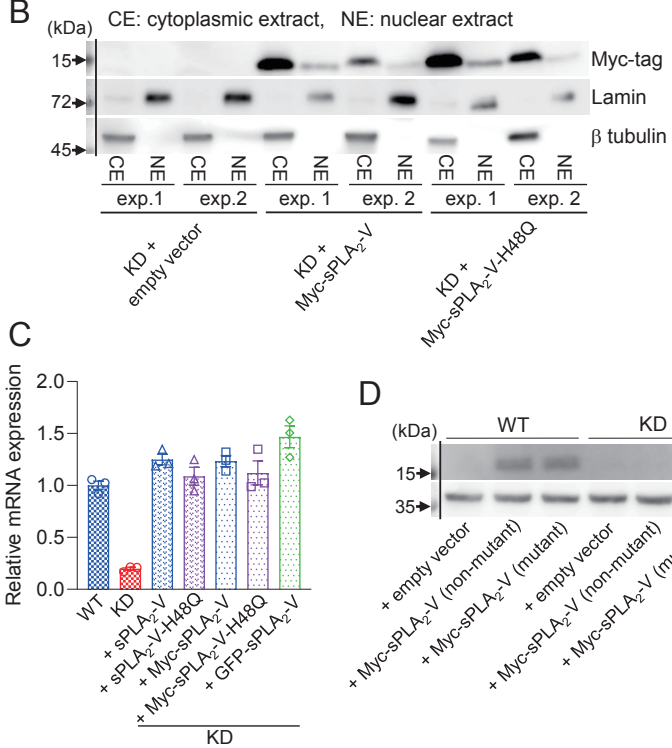

D

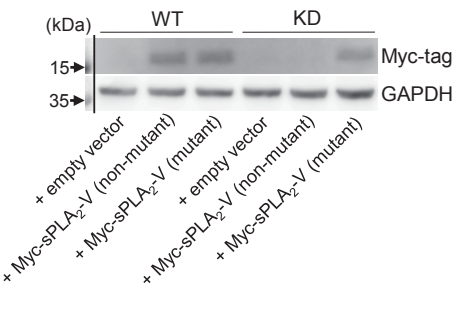

Fig. 2. Nuclear localization of GFP-tagged sPLA2-V and Myc-sPLA2-V and efficacy of knockdown of sPLA2-V by shRNA and transfection of various types of sPLA2-V in sPLA2-V KD RAW264.7 cells

A, sPLA2-V KD RAW264.7 cells were transfected with plasmid vectors encoding GFP alone or GFP-tagged sPLA2-V. GFP-tagged ${ }_{s P L A}-\mathrm{V}$ was detected in the nucleus as well as in the cytoplasmic area. Scale bars were $10 \mu \mathrm{m}$. B, Immunoblotting analysis of nuclear (NE) and cytoplasmic (CE) fractions from sPLA2-V KD cells transfected with empty vector and sPLA2-V KD cells expressing Myc-tagged sPLA2-V and Myc-tagged sPLA2-V H48Q using antiMyc-tag antibody, anti-Lamin antibody (nucleus marker), and anti- $\beta$ tubulin (cytoplasmic marker). Duplicate experiments were performed (exp. 1, exp. 2) in cells at baseline. C, RT-PCR shows successful knockdown of sPLA $2-\mathrm{V}$ after transfection with shRNA for sPLA2-V and re-constitutive expression of sPLA2-V, sPLA2-VH48Q, Myc-tagged sPLA2-V, Myc-tagged sPLA2-V-H48Q, or GFP- sPLA2-V in sPLA2-V KD RAW264.7 cells. D, Evaluation of efficacy of shRNA targeting sPLA2-V. Immunoblotting study using anti-Myc-tag antibody showed that shRNA targeting sPLA2-V effectively abolished expression of the transfected Myc-tagged nonmutant original sPLA2-V in sPLA2-V KD RAW264.7 cells. 
Table 1. ChIP-Seq peak annotations

\begin{tabular}{|c|c|c|c|}
\hline Genes & Binding & Chromosome & Distance to TSS $(\mathrm{kb})$ \\
\hline$P g k 1$ & WT, H48Q & $\mathrm{X}$ & 0 \\
\hline 4930467E23Rik & WT & 8 & 33 \\
\hline 6530403H02Rik & KD, WT, H48Q & 3 & 169 \\
\hline Atp $8 b 5$ & KD, WT, H48Q & 4 & 34 \\
\hline Dlgap1 & H48Q & 17 & 179 \\
\hline Elavl2 & H48Q & 4 & -236 \\
\hline F9 & H48Q & $\mathrm{X}$ & -69 \\
\hline Frem3 & KD, WT, H48Q & 8 & 30 \\
\hline$G m 5458$ & KD, WT, H48Q & 14 & 185 \\
\hline $\operatorname{Inpp} 4 b$ & $\mathrm{KD}$ & 8 & -19 \\
\hline $\operatorname{Lrrc4c}$ & WT, H48Q & 2 & 1199 \\
\hline Mapk10 & $\mathrm{KD}$ & 5 & -29 \\
\hline Mdfic & H48Q & 6 & 482 \\
\hline Mir101c & H48Q & 9 & 38 \\
\hline Mir101c & H48Q & 9 & 35 \\
\hline Mir101c & H48Q & 9 & 18 \\
\hline Poc5 & KD, WT, H48Q & 13 & -28 \\
\hline Sel1l & $\mathrm{KD}, \mathrm{WT}$ & 12 & -322 \\
\hline Slc22a22 & WT, H48Q & 15 & 57 \\
\hline Slc22a26 & H48Q & 19 & -17 \\
\hline Zic3 & H48Q & $\mathrm{X}$ & 308 \\
\hline
\end{tabular}

ChIP-Seq peaks were called using the MACS2 algorithm with a $P$ value of $<0.05$ and then annotated using ChIPseeker. The input sample was used by MACS and PeakSeq as a negative control when scoring significant peaks. WT, nucleus of sPLA2-V knockdown (KD) RAW 264.7 cells with re-constitutive expression of Myc-tagged sPLA2-V; H48Q, nucleus of sPLA2-V KD RAW 264.7 cells with expression of Myc-tagged sPLA2-V H48Q; KD, nucleus of sPLA2-V KD RAW 264.7 cells transfected with empty vector.

previously experienced technical problems partly due to unavailability of antibodies that specifically detect sPLA $_{2}-\mathrm{V}$ in tissues by immunoblotting ${ }^{16)}$, we performed immunoblotting analyses using an antiMyc-tag antibody in sPLA2-V KD RAW264.7 cells that had re-constitutive expression of C-terminally Myc-tagged sPLA2-V (KD + Myc-sPLA2-V) or Myctagged sPLA2-V-H48Q (KD+ Myc-sPLA2-V-H48Q). In agreement with the results obtained by immunofluorescence and fluorescence microscopic studies, immunoblotting of subcellular fractions revealed that Myc-tagged sPLA2-V and Myc-tagged ${ }_{s} \mathrm{PLA} 2-\mathrm{V}-\mathrm{H} 48 \mathrm{Q}$ protein was detected in the nuclear fraction as well as the cytoplasmic fraction, although their expression levels in the nuclear fraction appeared to be much lower than those in the cytoplasmic fraction (Fig. 2B). The successful purification of nuclear extracts was confirmed by the absence of $\beta$ -tubulin, a cytoplasmic marker, in the nuclear extract (Fig. 2B). RT-PCR showed successful knockdown of sPLA2-V after transfection of RAW264.7 cells with shRNA specific for sPLA2-V and successful expression of sPLA2-V, sPLA2-V-H48Q, Myc-tagged sPLA2-V,
Myc-tagged sPLA2-V-H48Q, and GFP-sPLA2-V in sPLA2-V KD RAW264.7 cells after transfection with the respective plasmid vectors (Fig. 2C). Immunoblotting study using anti-Myc-tag antibody showed that shRNA targeting sPLA2-V effectively abolished expression of the transfected Myc-tagged non-mutant original sPLA2-V in sPLA2-V KD RAW264.7 cells (Fig. 2D).

\section{ChIP-Seq and ChIP-qPCR in RAW264.7 Cells}

The results showing nuclear localization of ${ }_{s} \mathrm{PLA}_{2}-\mathrm{V}$ prompted us to examine a role for sPLA2-V in the nucleus by testing whether sPLA2-V binds to DNA in the nucleus using ChIP-sequence (seq) and ChIP-quantitative PCR (qPCR). ChIP-Seq peaks were called using the MACS2 algorithm with a $P$-value of $<0.05$, and then annotated using ChIPseeker (Table 1 and Supplementary Table 2; data are available at the NCBI Gene Expression Omnibus under accession number GSE156528). Upon selecting peaks with a $P$-value cutoff of 0.05 and an enrichment $>2$-fold over input, significant enrichment of 8,8 , and 16 peaks in the nucleus of sPLA2-V KD RAW264.7 cells transfected with empty 
vector, sPLA2-V KD RAW264.7 cells with re-constitutive expression of Myc-tagged sPLA2-V, and sPLA2-V KD RAW264.7 cells expressing Myc-tagged sPLA2-V-H48Q, respectively, was seen (Supplementary Table 2). Among the significant peaks, the region corresponding to $-375 \sim+6$ from the transcriptional start site of the Pgk1 gene was the strongest binding peak in the nucleus of both sPLA2-V KD cells expressing Myc-tagged sPLA2-V (fold-enrichment $[\mathrm{FE}]=222.82965, P$-value $<\mathrm{E}^{-1000}$ ) and $s \mathrm{PLA}_{2}-\mathrm{V} \mathrm{KD}$ cells expressing Myc-tagged sPLA2-V-H48Q $\left(\mathrm{FE}=113.3403, P\right.$-value $<\mathrm{E}^{-300}$; Fig. $3 \mathrm{~A}$, and Supplementary Table 2). The other genes that had a significant peak had FE $<10$ (Supplementary Table 2). Meanwhile, the Pgk1 gene was not identified as a significant peak in the nucleus of ${ }_{5} \mathrm{PLA}_{2}-\mathrm{V} \mathrm{KD}$ cells transfected with empty vector (Supplementary Table 2). Myc-tagged sPLA2-V binding at the locus was validated by ChIP-qPCR (Fig.3B). The primers covered the binding regions obtained from ChIP-Seq. The Pgk1 gene showed enrichment in the ChIP using an antibody against Myc-tag as compared to the control IgG (Fig.3B). Thus, sPLA2-V might bind to the upstream region of the Pgk1 gene in the nucleus.

\section{Pgk1 Gene Promoter Activity in RAW264.7 Cells}

Next, we examined whether sPLA2-V in the nucleus can regulate transcriptional activity of the Pgkl gene. A comparison of the relative luciferase activity showed that sPLA2-V KD RAW264.7 cells had lower promoter activity compared to sPLA2-V WT RAW264.7 cells (Fig.3C). This result indicated that the transcriptional activity of Pgk1 was inhibited in $s^{P L A} 2-V$ KD RAW264.7 cells. The inhibition of the relative luciferase activity in sPLA2-V KD cells was reversed by re-constitutive expression of ${ }_{3} \mathrm{PLA}_{2}-\mathrm{V}$ or sPLA2-V-H48Q that lacks enzymatic activity ${ }^{19)}$ (Fig.3C). Taken together, these results indicate that sPLA2-V promoted transcriptional activity of the Pgk1 gene independently of its enzymatic activity in RAW264.7 cells.

Binding, Internalization, and Degradation Assay of AcLDL in RAW264.7 Cells

Next, we determined whether sPLA2-V may have a role in endocytosis of AcLDL in RAW264.7 cells. The specific binding activity of ${ }^{125} \mathrm{I}$-labeled AcLDL was similar in sPLA2-V WT and sPLA2-V KD cells (Figs.4A and 4B). The amount of specific internalization of ${ }^{125}$ I-labeled AcLDL after $1 \mathrm{hr}$ incubation at $37^{\circ} \mathrm{C}$ was lower in sPLA2-V KD cells compared with sPLA2-V WT cells (Fig.4C). The assay of internalization was affected by simultaneous lysosomal degradation of the internalized AcLDL. The

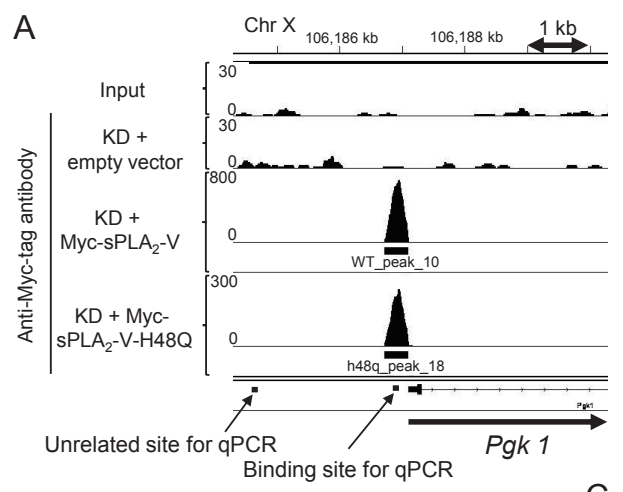

B
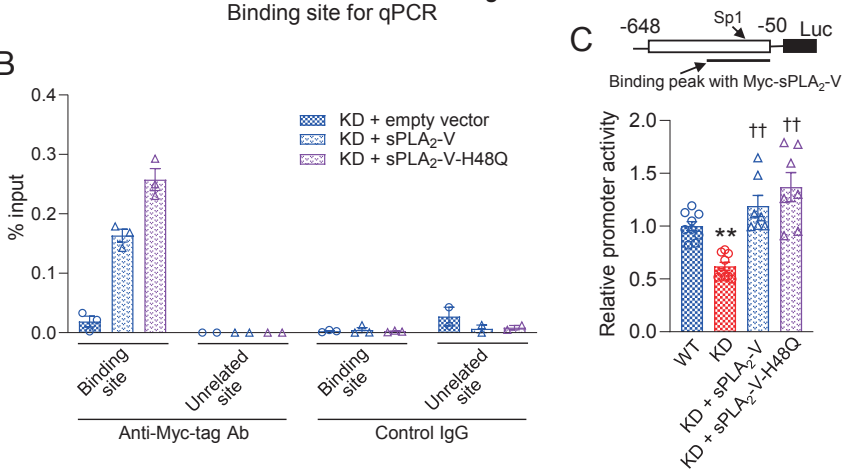

Fig.3. ChIP-seq and ChIP-qPCR analysis and promoter assay in RAW264.7 cells

A, Representative profile of peaks obtained for the Pgk1 gene by ChIP-Seq. ChIP-seq was performed using sPLA2-V KD cells transfected with empty vector, sPLAz-V KD cells expressing Myctagged sPLA $2-\mathrm{V}$, and sPLA2-V KD cells expressing Myc-tagged sPLA2-V-H48Q using an anti-Myc-tag mouse monoclonal antibody. Input of $s \mathrm{PLA}_{2}-\mathrm{V} \mathrm{KD}$ cells expressing Myc-tagged sPLA2-V was used as a ChIP-seq control. ChIP-seq analysis showed a Myc-tagged sPLA2-V-binding peak at the upstream region of Pgk1 gene locus. B, ChIP-qPCR validation of Myc-tagged sPLA2-V binding to the $P g k 1$ gene. Data are shown as a percentage expression of input control. The amplification sites (binding site and unrelated site) for PCR are indicated in panel A (ChIP-seq). Each bar represents the mean \pm SEM of 2-3 independent experiments. C, Promoter assay for Pgk1 gene transcriptional activity. sPLA2-V WT cells, sPLA2-V KD cells, and sPLA2-V KD cells with re-constitutive expression of sPLA2-V or sPLA2-V-H48Q were transfected with Cypridina and Renilla luciferase expression vectors. The promoter activity is expressed as the relative luciferase activity normalized to Renilla activity. Values in each bar were normalized to that of WT $(=1)$. Each bar represents the mean \pm SEM of 6-9 independent experiments. ${ }^{* *}, P<0.01$ vs. WT. $^{\dagger \dagger}, P$ $<0.01$ vs KD. Upper panel shows a schematic illustration of the promoter construct used in this Cypridina luciferase reporter assay.

magnitude of the specific internalization of ${ }^{125} \mathrm{I}$-labeled AcLDL continued to be lower in sPLA2-V KD cells compared to sPLA2-V WT cells, even when bafilomycin A1 (Baf A), a lysosomal inhibitor, was co-incubated to block simultaneous degradation of the internalized ${ }^{125}$ I-labeled AcLDL (Fig.4D). The specific degradation of AcLDL was significantly lower in sPLA2-V KD cells compared to sPLA2-V WT cells 

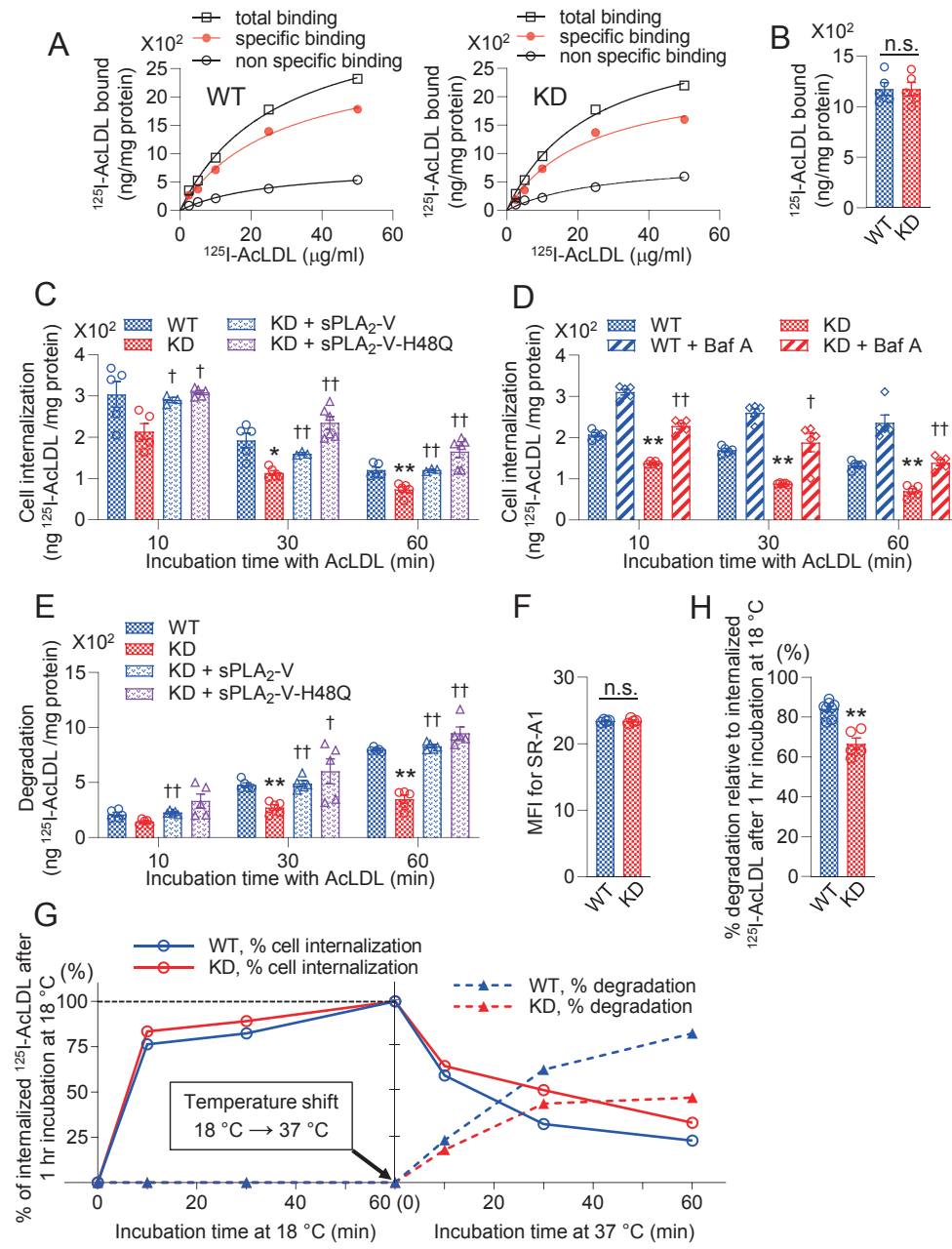

Fig.4. Impairment of AcLDL internalization and degradation in sPLA2-V KD RAW264.7 cells

Each bar represents the mean \pm SEM of 5-8 independent experiments. Details of the methods are described in the text. A, Dose-response binding of ${ }^{125} \mathrm{I}$-labeled AcLDL to the cell surface of sPLA2-V WT cells (left panel) and sPLA2-V KD cells (right panel) after incubation for 2 hr. B, sPLA2-V WT and -KD cells show similar degrees of cell surface-specific binding of ${ }^{125}$ I-labeled AcLDL after incubation with $20 \mu \mathrm{g}$ ${ }^{125} \mathrm{I}$-labeled AcLDL for $2 \mathrm{hr}$. n.s. indicates statistically not significant. C, Comparison of specific internalization of ${ }^{125}$ I AcLDL in sPLA2-V WT cells, sPLA2-V KD cells, and sPLA2-V KD cells with re-constitutive expression of sPLA2-V WT or sPLA2-V-H48Q that lacks enzymatic activity. ${ }^{*}, P<0.05,{ }^{* *}, P<0.01$ vs. WT. ${ }^{\dagger}, P<0.05,{ }^{\dagger} \uparrow, P<0.01$ vs KD. D, Effect of the lysosomal inhibitor bafilomycin A1 (Baf A) on specific internalization of ${ }^{125} \mathrm{I}$ AcLDL. Cells were similarly incubated with ${ }^{125} \mathrm{I}$ AcLDL for $2 \mathrm{hr}$ at $4{ }^{\circ} \mathrm{C}$, washed, and then further incubated for the indicated time at $37^{\circ} \mathrm{C}$ in the presence or absence of $1 \mu \mathrm{M}$ Baf A. The specific internalization was compared. ${ }^{* *}, P<0.01 \mathrm{vs.} \mathrm{WT.}{ }^{\dagger}, P<$ $0.05,{ }^{\dagger}, P<0.01$ vs WT + Baf A. E, Comparison of the specific degradation of AcLDL at the indicated time after incubation with AcLDL. **, $P<0.01$ vs. WT. ${ }^{\dagger}, P<0.05,{ }^{\dagger \dagger}, P<0.01$ vs KD. F, Comparison of magnitude of cell surface expression of SR-A1 between sPLA2-V WT and KD cells. MFI indicates mean fluorescence intensity. G, Pulse chase experiment in RAW264.7 cells. Intracellular processing of internalized ${ }^{125} \mathrm{I}$ AcLDL for lysosomal degradation. Cells were incubated for the indicated time up to $1 \mathrm{hr}$ with ${ }^{125} \mathrm{I}$-AcLDL at $18^{\circ} \mathrm{C}$. The cells were then washed and a portion of the cells was taken to measure specific internalization of AcLDL. The remaining cells were further incubated for the indicated time up to $1 \mathrm{hr}$ at $37^{\circ} \mathrm{C}$, and TCA-soluble radioactivity was measured at each time point. The amount of the internalized and degraded AcLDL (per cell protein) at each time point was normalized to that of internalized AcLDL after incubation for $1 \mathrm{hr}$ at $18^{\circ} \mathrm{C}(=100 \%)$. The mean amount of internalized AcLDL after the incubation for $1 \mathrm{hr}$ at $18^{\circ} \mathrm{C}$ was $481 \mathrm{ng} / \mathrm{mg}$ protein and $378 \mathrm{ng} / \mathrm{mg}$ protein for sPLA2-V WT cells and sPLA2-V KD cells, respectively. The data are representative of three experiments. H, Comparison of degradation relative to internalized ${ }^{125} \mathrm{I}-\mathrm{AcLDL}$ after $1 \mathrm{hr}$ incubation at $18^{\circ} \mathrm{C}$ on the pulse chase experiment (panel G) between sPLAz-V WT cells and sPLA $2-V$ KD cells. sPLA2-V KD cells had lower rate (percentage) of degraded AcLDL after $1 \mathrm{hr}$ incubation at $37^{\circ} \mathrm{C}$ relative to the amount of the specific internalized AcLDL after $1 \mathrm{hr}$ incubation at $18^{\circ} \mathrm{C}$. The rate reflects translocation of internalized AcLDL to the lysosome compartment. $n=5$ in each experiment. ${ }^{* *}, P<0.01$ vs. WT.

(Fig.4E). Impairment of internalization and degradation of AcLDL in sPLA2-V KD cells was reversed by re-constitutive expression of sPLA2-V WT or sPLA2-V-H48Q (Figs.4C and 4E). Magnitude of cell-surface expression of SR-A1, a main AcLDL receptor, was comparable between sPLA2-V WT and

\section{Advance Publication Journal of Atherosclerosis and Thrombosis


sPLA2-V KD cells (Fig.4F), a result that was comparable with that regarding the binding activity of ${ }^{125} \mathrm{I}$ AcLDL. Together, sPLA2-V in RAW264.7 cells has a crucial role in the internalization and degradation of AcLDL that may be mediated via a mechanism that is independent of its enzymatic activity.

\section{Pulse-chase Experiment in RAW264.7 Cells}

Next, we examined a role for sPLA2-V in intracellular processing of internalized AcLDL. RAW264.7 cells were incubated with ${ }^{125} \mathrm{I}$ AcLDL at $18^{\circ} \mathrm{C}$ for the indicated time up to $1 \mathrm{hr}$. At this temperature, ${ }^{125} \mathrm{I}$ AcLDL bound to cell-surface receptors will be internalized and accumulate in early endosomes without further processing or fusion of early endosomes to late endosome/lysosomes ${ }^{21)}$ (Fig. 4G). After incubation at $18^{\circ} \mathrm{C}$, the treated cells were washed to remove unbound ${ }^{125} \mathrm{I}$ AcLDL and chased at $37^{\circ} \mathrm{C}$ for the indicated time up to $1 \mathrm{hr}$. The amount of the internalized and degraded AcLDL (per cell protein) at each time point was normalized to that of the internalized AcLDL after incubation for $1 \mathrm{hr}$ at $18^{\circ} \mathrm{C}(=100 \%)$. Intracellular processing of internalized AcLDL for lysosomal degradation was defined as percentage of the amount of degraded ${ }^{125} \mathrm{I}$ AcLDL after incubation for $1 \mathrm{hr}$ at $37^{\circ} \mathrm{C}$ relative to that of the internalized ${ }^{125} \mathrm{I}$ AcLDL after incubation for $1 \mathrm{hr}$ at $18^{\circ} \mathrm{C}$. After shifting the temperature to $37^{\circ} \mathrm{C}$, sPLA2-V $\mathrm{KD}$ cells had a lower rate of AcLDL degradation compared with sPLA2 $-\mathrm{V}$ WT cells (Fig.4H). These results indicated an impairment of intracellular processing of internalized AcLDL for lysosomal degradation in sPLA2-V KD RAW264.7 cells.

Maturation of Endosomes Containing AcLDL and Its Translocation to Lysosomes in RAW264.7 Cells

To evaluate maturation of endosomes containing AcLDL, we examined whether the intracellularly internalized AcLDL co-localized with endosomal proteins that are recruited to maturing endosomes in RAW264.7 cells. In the immunofluorescence study, intracellular AcLDL co-localized with Rab5, an early endosome marker, 5 min after incubation with AcLDL (Fig. 5A). Sequentially, AcLDL co-localized with Rab7, a late endosomal marker, 5-30 min after incubation with AcLDL. Next, to evaluate translocation of the intracellularly internalized AcLDL to lysosomes, we incubated RAW264.7 cells with AcLDL conjugated with pHrodo, a $\mathrm{pH}$ indicator that emits green fluorescence under acidic conditions. Green fluorescence from pHrodo conjugated to AcLDL appeared in the RAW264.7 cells 30 and 60 min after co-incubation (Fig. 5B). These results indicated that endosomes containing AcLDL had matured and were translocated to lysosomes. Compared with sPLA2-V WT cells, sPLA2-V KD cells had lower amounts of fluorescence emission from pHrodo conjugated to AcLDL, and this decrease was restored by re-constitutive expression of sPLA2-V or sPLA2-V-H48Q that lacks catalytic enzymatic activity (Fig.5C). We further examined lysosomal acidification using LysoTracker Red that is membrane permeable and accumulates in acidic organelles including lysosomes (Figs.5D and 5E). After incubation for $30 \mathrm{~min}$ with $50 \mathrm{nM}$ LysoTracker Red, the extent of red fluorescence from LysoTracker was similar between sPLA2-V WT and KD cells (Fig. 5D), suggesting that both cell types had similar lysosomal acidification. Thus, the low fluorescence intensity of pHrodo conjugated to AcLDL in sPLA2-V KD cells could be attributed to impaired translocation of AcLDL conjugated with pHrodo to the lysosome but not dysfunctional lysosomal acidification. Taken together, sPLA2-V knockdown impaired translocation of the intracellularly internalized AcLDL to the lysosome, and sPLA2-V played a role in the translocation of internalized AcLDL to the lysosome independently of its enzymatic activity. These results were also consistent with those obtained for the pulsechase experiment using ${ }^{125}$ I AcLDL.

\section{Reduced Actin Polymerization in sPLA2-V KD RAW264.7 Cells}

We assessed the degree of actin polymerization in response to AcLDL by flow cytometry using Alexa Fluor 546-phalloidin ${ }^{22)}$ in RAW264.7 cells because actin polymerization has an important role in the early stage of endocytic vesicle internalization and translocation of cargo from early endosomes to late endosomes/lysosomes ${ }^{23,24)}$. The degree of actin polymerization in response to AcLDL was lower in ${ }_{s} P L A_{2}-\mathrm{V}$ KD cells compared to $\mathrm{sPLA}_{2} \mathrm{~V}$ WT cells (Figs.6A and 6B). The impairment of actin polymerization in response to AcLDL in sPLA2-V KD cells was reversed by re-constitutive expression of ${ }_{s} \mathrm{PLA}_{2}-\mathrm{V}$ or $\mathrm{sPLA}_{2}-\mathrm{V}-\mathrm{H} 48 \mathrm{Q}$ after transfection with the respective expression vectors (Fig.6B). Thus, sPLA2-V appears to have a crucial role in actin polymerization in response to AcLDL via mechanisms that are independent of its enzymatic activity in RAW264.7 cells.

PGK1 Expression, Beclin1 Phosphorylation and class III PI3-kinase Activity and Their Relation with Actin Polymerization and Translocation of Internalized AcLDL to Lysosomes in RAW264.7 Cells It was shown that PGK1 phosphorylates Beclin1 

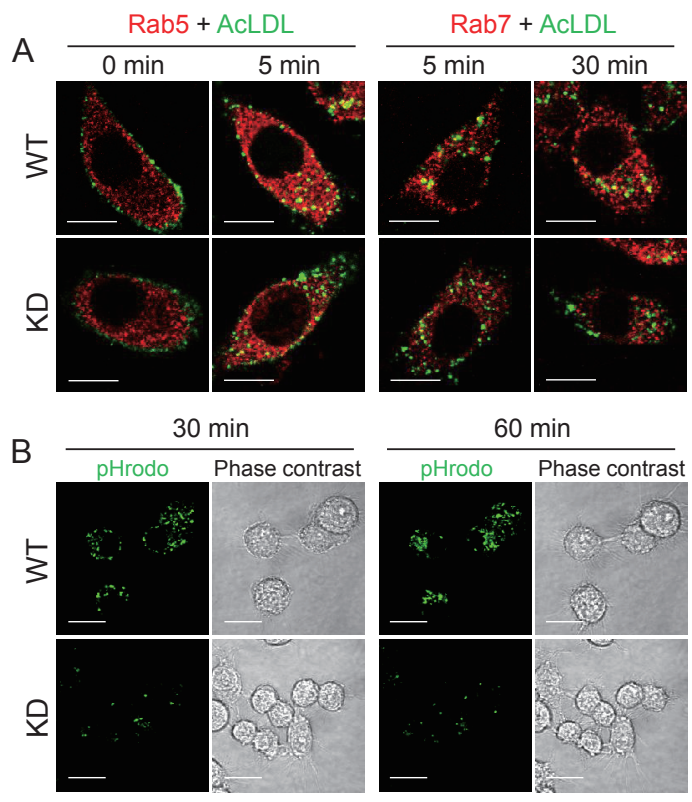

C
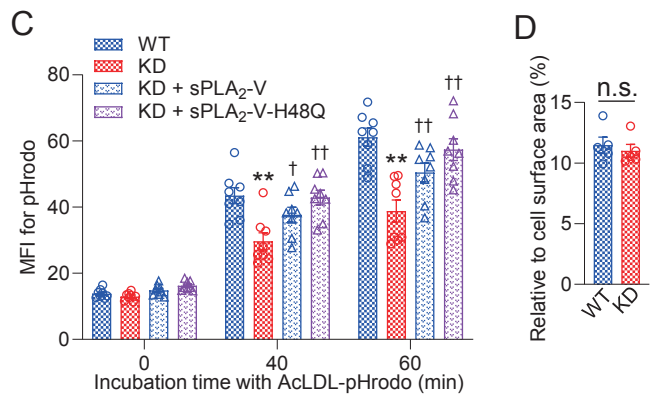

E

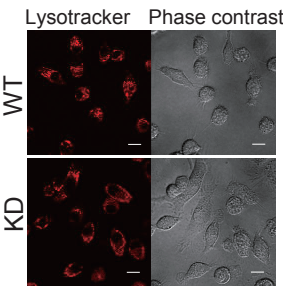

Fig. 5. Maturation of endosomes containing AcLDL and fusion of endosomes and lysosomes in RAW264.7 cells

A, Immunofluorescence images showing colocalization of Alexa Fluor ${ }^{\mathrm{TM}} 488$ AcLDL (green) with Rab5 and Rab7 (red) after incubation with AcLDL for the indicated times in sPLA2-V WT and KD cells. Scale bars were $10 \mu \mathrm{m}$. The data are representative of three experiments. B, Fluorescence images of AcLDL conjugated with pHrodo (green) to visualize acidic cell compartments after incubation for the indicated times are also shown. Scale bars were $10 \mu \mathrm{m}$. Right panels are phase contrast images corresponding to the respective fluorescence images of AcLDL conjugated with pHrodo. The data are representative of three experiments. C, Comparison of the mean fluorescence intensity (MFI) of pHrodo at the indicated time after incubation with AcLDL conjugated with pHrodo for sPLA2-V WT cells, sPLA2-V KD cells, and sPLA2-V $\mathrm{KD}$ cells with re-constitutive expression with sPLA2-V or sPLA2-V-H48Q that lacks enzymatic activity. $n=5$ -7 in each experiment. ${ }^{* *}, P<0.01$ vs. WT. ${ }^{*}, P<$ $0.05,{ }^{\dagger}, P<0.01$ vs. KD. D, Comparison of the area exhibiting LysoTracker Red fluorescence that represents acidic cell compartments between sPLA2-V WT and $-\mathrm{KD}$ cells. Cells were incubated with $50 \mathrm{nM}$ LysoTracker Red for $30 \mathrm{~min}$ in RPMI medium. The area of red fluorescence in each cell was measured using ImageJ and expressed as the percentage of red fluorescence area relative to the cell surface area, and averaged over at least 20 cells. $n=5$ in each experiment. n.s. indicates statistically not significant. E, Panel shows representative confocal microscopic images. Scale bars are $10 \mu \mathrm{m}$.
A
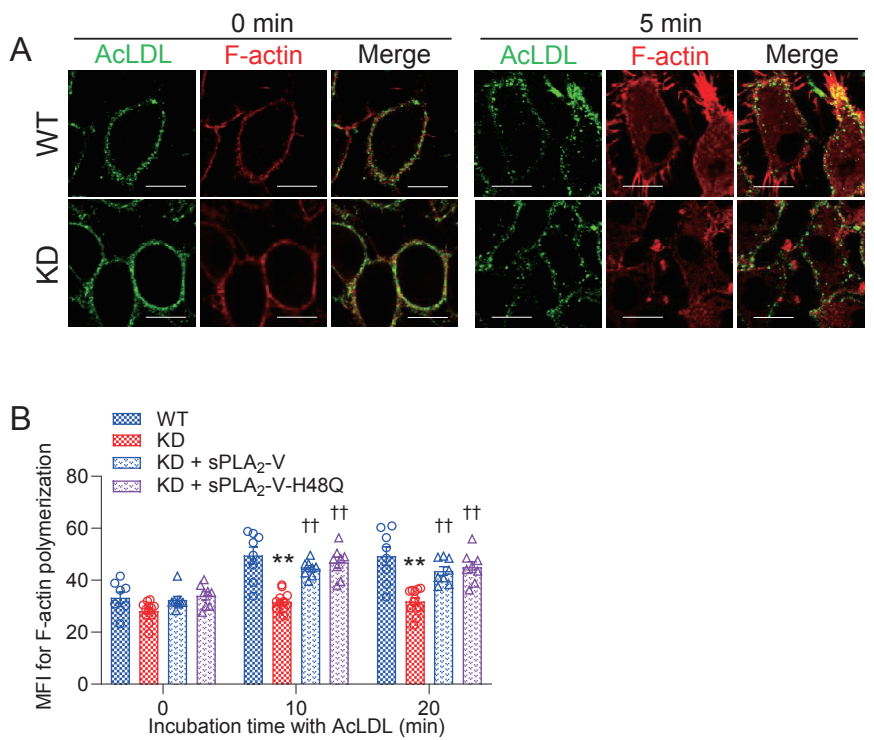

Fig. 6. Impairment of actin polymerization in sPLA2-V KD RAW264.7 cells

A, Confocal microscopy of F-actin polymerization detected by Alexa Fluor 546-phalloidin (red) at baseline $(0 \mathrm{~min})$ and $5 \mathrm{~min}$ after incubation with Alexa Fluor 488-labelled AcLDL (green) in sPLA2-V WT and -KD cells. Cell protrusions probably due to actin polymerization are seen $5 \mathrm{~min}$ after incubation with AcLDL. Scale bars were $10 \mu \mathrm{m}$. B, Comparison of mean fluorescence intensity (MFI) of F-actin polymerization using flow cytometry after incubation with AcLDL for the indicated time for sPLA2-V WT, sPLA2-V KD, and sPLA2-V KD cells with re-constitutive expression of sPLA2-V or sPLA2-V-H48Q. $n=5-7$ in each experiment. $^{* *}, P<0.01$ vs. WT. ${ }^{\dagger \dagger}, P<0.01$ vs. KD. 

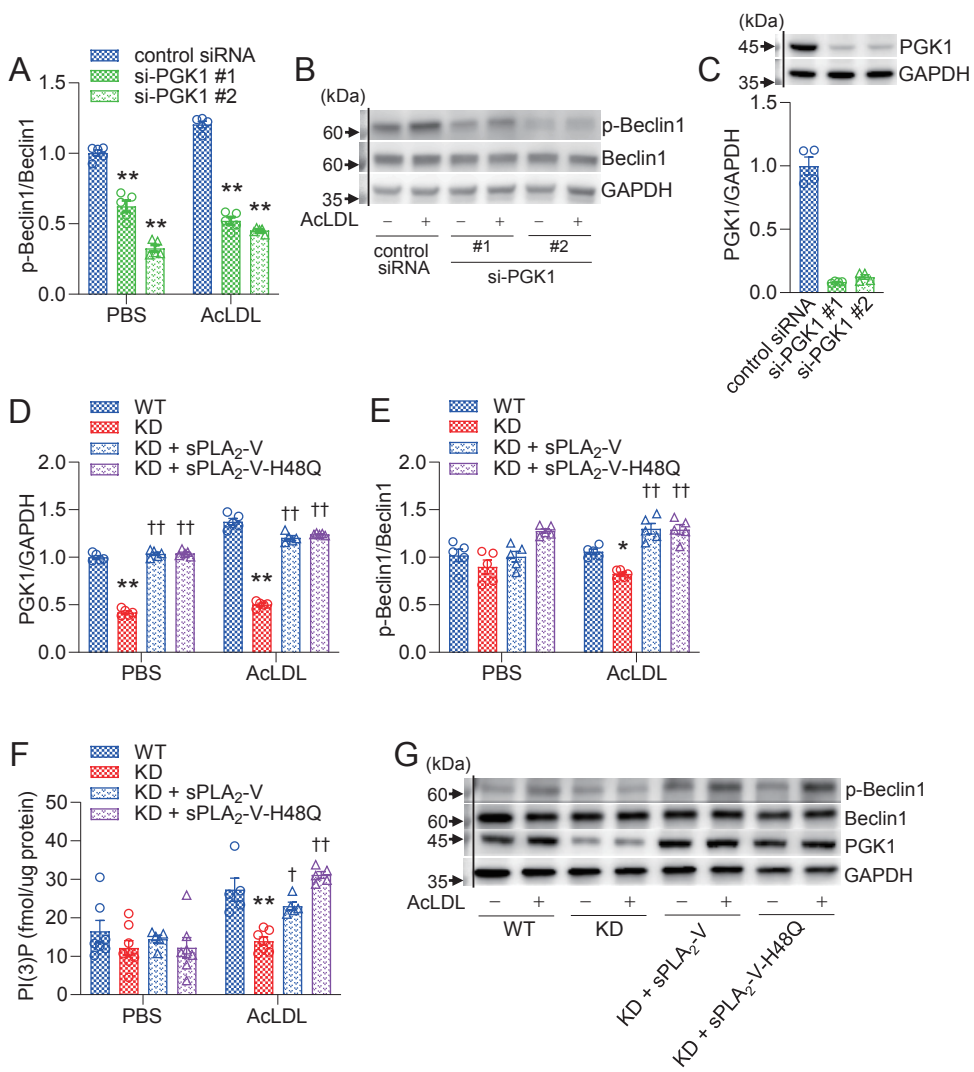

Fig.7. PGK1 expression, Beclin1 S30 phosphorylation, and PI3-kinase activity in RAW264.7 cells

A, Suppression of Beclin1 phosphorylation at S30 (p-Beclin1/Beclin1) by siRNA (\#1 and \#2)-mediated reduction of PGK1 expression. Values were normalized to that of control siRNA after incubation with PBS as a vehicle $(=1) . n=5$ in each experiment. ${ }^{* *}, P<0.01$ vs. control siRNA. B, Representative immunoblots for panel A. C, Successful suppression of PGK1 expression by siRNA confirmed by immunoblotting. D, E, F, Comparison of PGK1 expression (D), Beclin1 phosphorylation at S30 (E), and PI3-kinase activity (F) after incubation for 2 hr with $20 \mu \mathrm{g} / \mathrm{mL}$ AcLDL or PBS as a vehicle in sPLA2-V-WT and KD cells, and sPLA2-V KD cells with re-constitutive expression of sPLA2-V or sPLA2-V-H48Q. G, Representative immunoblots showing PGK1 expression and Beclin1 phosphorylation in various types of RAW264.7 cells. Values in panels D and E were normalized to that of WT after incubation with PBS as a vehicle $(=1)$. Each bar represents the mean \pm SEM of 5-6 independent experiments. ${ }^{*}, P<0.05,{ }^{* *}, P<0.01$ vs. WT, ${ }^{\dagger}, P<0.05,{ }^{\dagger}{ }^{\dagger}, P<0.01$ vs. KD.

at the active site (S30), leading to enhancement of Beclin1-VPS34 complex (class III PI3-kinase) activity toward phosphatidylinositol 3-phosphate (PI[3]P) production ${ }^{12,}{ }^{13)}$. In agreement with these previous reports ${ }^{12,13)}$, reduction of PGK1 expression by siRNA suppressed Beclin1 S30 phosphorylation in sPLA2-V WT cells (Figs.7A and 7B). Successful suppression of PGK1 expression by siRNA was confirmed by immunoblotting (Fig.7C). Compared with sPLA2-V WT cells, sPLA2-V KD cells had lower levels of PGK1 expression (Fig.7D), Beclin1 S30 phosphorylation (Fig.7E), and class III PI3-kinase activity (Fig.7F), and these levels were restored by re-constitutive expression of ${ }_{3} P_{2} A_{2}-\mathrm{V}$ or sPLA2-V-H48Q. Representative immunoblots to assess PGK1 expression and Beclin 1 phosphorylation are shown in Fig.7G. Taken together, sPLA2-V regulates the PGK1-
Beclin1-class III PI3-kinase pathway in a manner that is independent of its enzymatic activity in RAW264.7 cells.

In sPLA2-V WT cells, suppression of PGK1 or Beclin 1 expression by respective siRNAs impaired actin polymerization in response to AcLDL (Fig. 8A) and translocation of internalized AcLDL to lysosomes (Fig. 8B) as estimated by flow cytometry using Alexa Fluor 546-phalloidin and pHrodo-conjugated AcLDL, respectively. Successful suppression of Beclin 1 expression by siRNA was confirmed by immunoblotting (Fig. 8C). The impairment of actin polymerization and translocation of AcLDL to lysosomes in sPLA2-V KD RAW264.7 cells was reversed by overexpression of PGK1 (Figs. 8D and $8 \mathrm{E})$. An immunoblotting analysis confirmed successful expression of PGK1 after transfection of a plasmid

\section{Advance Publication Journal of Atherosclerosis and Thrombosis}



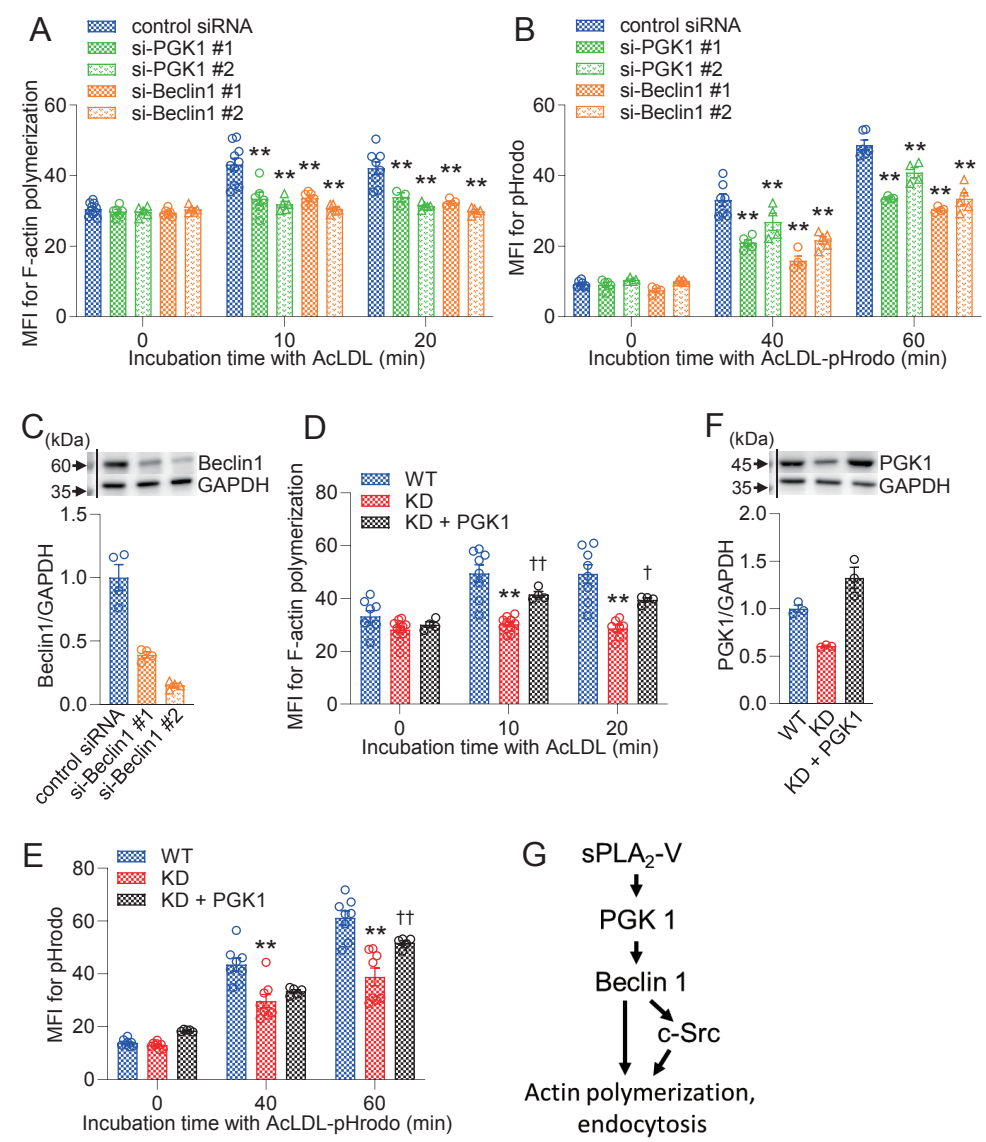

Fig. 8. Role of PGK1-Beclin1 in actin polymerization and translocation of AcLDL to lysosomes in RAW264.7 cells

A and B, siRNA-mediated reduction in PGK1 or Beclin1 expression (\#1 and \#2) inhibited actin polymerization (A) and translocation of internalized AcLDL conjugated with pHrodo (B). Actin polymerization was assessed by detection of F-actin polymerization with Alexa Fluor 546-phalloidin. Translocation of AcLDL to lysosomes was assessed using flow cytometry of pHrodo-conjugated AcLDL. Details of the methods are described in the text. Each bar represents the mean \pm SEM of 5 independent experiments. ${ }^{* *}, P<0.01$ vs. control siRNA. C, Reduction of Beclin1 protein expression by siRNAs (\#1 and \#2). Values were normalized to that of control siRNA $(=1)$. Upper panel shows representative immunoblots. D and E, Transfection of an expression vector to overexpress PGK1 reversed a decrease in actin polymerization (D) and translocation of internalized AcLDL conjugated with pHrodo (E). Details of methods are described in the text. Each bar represents the mean \pm SEM of 5 independent experiments. ${ }^{* *}, P<0.01$ vs. WT, ${ }^{\dagger}, P<0.05,{ }^{\dagger}, P<0.01$ vs. KD. F, Successful overexpression of PGK1 protein by transfection of sPLA2-V KD RAW264.7 cells with a plasmid vector encoding Pgk1. Values were normalized to that of WT $(=1)$. G, Schematic representation of a potential mechanism for sPLA2-V mediated endocytosis of AcLDL in RAW264.7 cells.

vector encoding the Pgk1 gene in sPLA2-V KD cells (Fig. 8F). Thus, the PGK1-Beclin1 pathway appears to regulate actin polymerization in response to AcLDL and translocation of internalized AcLDL to lysosomes in RAW264.7 cells. Moreover, sPLA2-V contributes to actin polymerization and translocation of internalized AcLDL to lysosomes through the PGK1-Beclin 1 pathway in RAW264.7 cells (Fig. 8G).

Role of c-Src in Actin Polymerization and Translocation of AcLDL to Lysosome

Endocytosis is an actin-dependent process ${ }^{23}$ 24), and a variety of intracellular signals can converge to modulate actin reassembly at endocytosis. When we searched for intracellular signals that could contribute to reducing actin polymerization in $s \mathrm{PLA}_{2}-\mathrm{V} \mathrm{KD}$ RAW264.7 cells, we observed reduced levels of c-Src phosphorylation at the active site (Y416) in sPLA2-V $\mathrm{KD}$ cells compared with that seen in sPLA2-V WT cells (Figs.9A and 9B). Overexpression of c-Src relieved impairment of actin polymerization in response to AcLDL and translocation of intracellularly internalized pHrodo-conjugated AcLDL to lysosomes in sPLA2-V KD cells (Figs.9C and 9D, respectively). The immunoblotting analysis confirmed successful expression of $\mathrm{c}-\mathrm{Src}$ after transfection of a plasmid vector encoding c-Src in sPLA2-V KD cells (Fig.9E). Suppression of PGK1, Beclin1, or VPS34 by the 

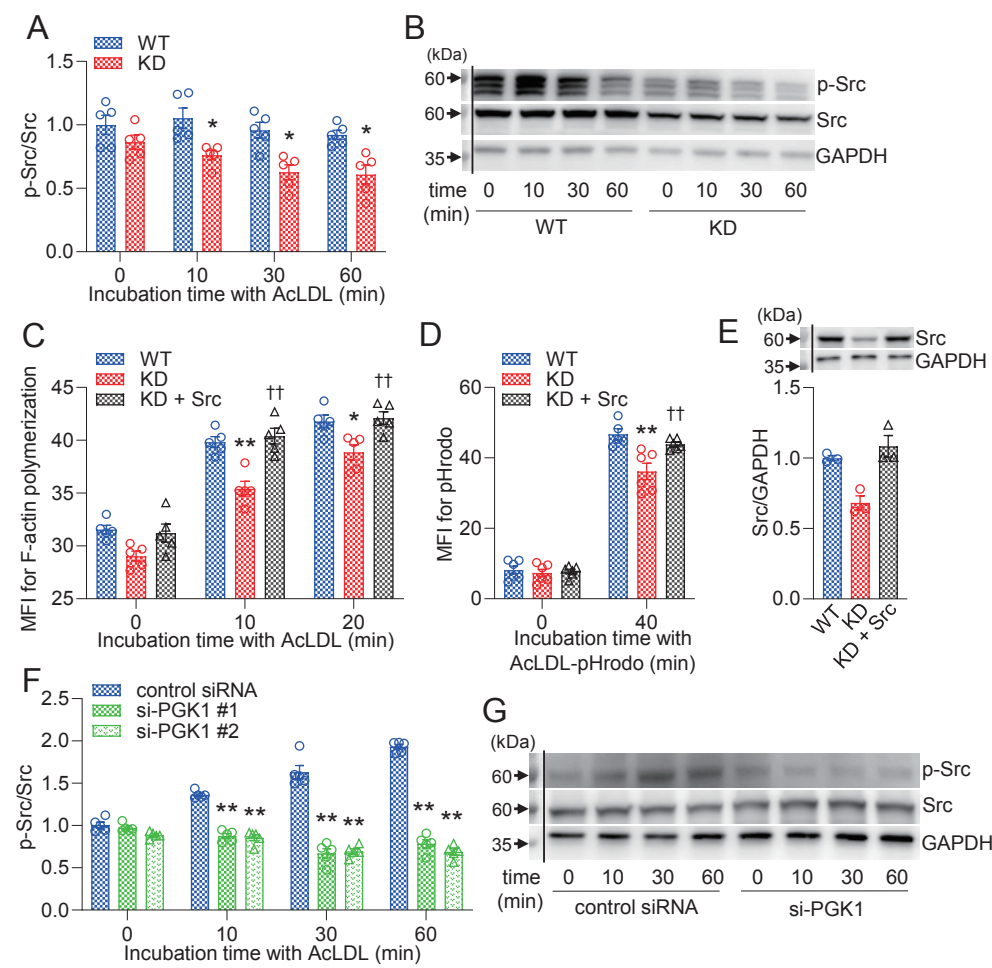

G
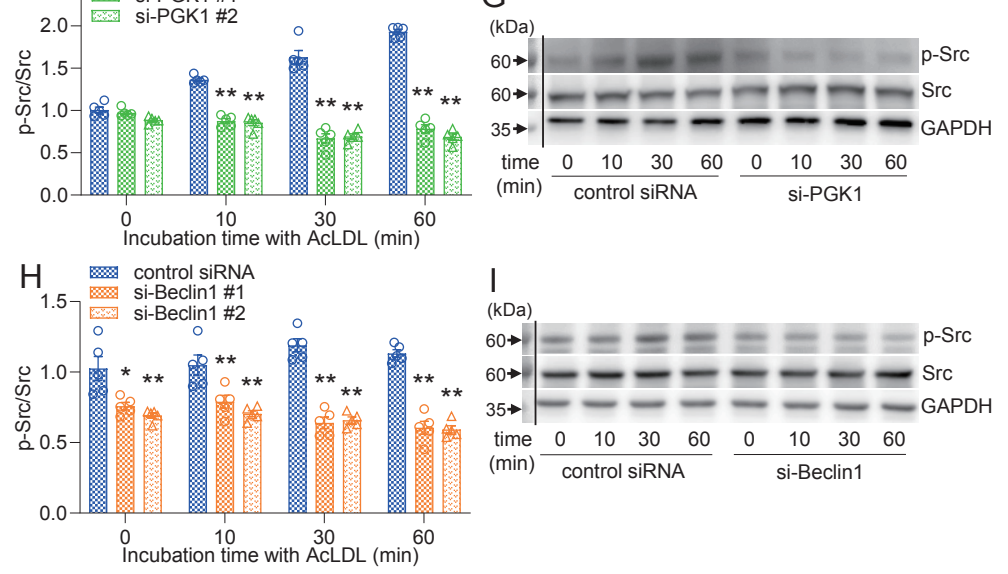

Fig. 9. c-Src phosphorylation and its role in actin polymerization and translocation of internalized AcLDL to lysosomes in RAW264.7 cells

A, Ratio of c-Src phosphorylation at the active site (Y416) relative to total c-Src in response to AcLDL was reduced in sPLA2-V KD cells compared with that for sPLA2-V WT cells. Data are expressed as values relative to the value of sPLA2 -V WT cells at baseline (incubation time 0) $(=1) . n=5$ in each experiment. ${ }^{*}, P<0.05$, vs. WT. B, Representative immunoblots for panel A. C and D, Overexpression of c-Src after transfection with an expression vector encoding the $c$-Src gene reversed an impairment of actin polymerization (C) and transport of internalized AcLDL conjugated with pHrodo to lysosomes (D) in sPLA2-V KD RAW264.7 cells. Details of the methods are described in the text. $n=5$ in each experiment. ${ }^{*}, P<0.05,{ }^{* *}, P<0.01$ vs. WT, ${ }^{\dagger \dagger}, P<0.01$ vs KD. E, Immunoblotting showing successful expression of c-Src protein driven by an expression vector used to transfect sPLA2-V KD RAW264.7 cells. Values were normalized to that of WT (=1). F, siRNA (\#1 and \#2)-mediated reduction of PGK1 suppressed c-Src phosphorylation at Y416 in response to AcLDL in sPLA2-V WT RAW264.7 cells. G, Representative immunoblots for panel F. H, siRNA-mediated reduction of Beclin1 suppressed c-Src phosphorylation at Y416 in response to AcLDL in sPLA2-V WT RAW264.7 cells. I, Representative immunoblots for panel $\mathrm{H}$. Values in panels $\mathrm{F}$ and $\mathrm{H}$ were normalized to that of control siRNA at baseline (incubation time 0$)(=1) . n=5$ in each experiment, ${ }^{*}, P<0.05,{ }^{*}, P<0.01$ vs. control siRNA.

respective siRNAs was associated with a reduction in c-Src phosphorylation at Y416 in sPLA2-V WT cells (Figs.9F, 9G, 9H, 9I, 10A, and 10B). Successful suppression of VPS34 expression by siRNA was confirmed by immunoblotting (Fig.10C). Taken together, reduction of c-Src phosphorylation at Y416 was an additional mechanism that mediated decreases in actin polymerization and translocation of internalized AcLDL to lysosomes in sPLA2-V KD RAW264.7 cells (Fig. 8G). PGK1-Beclin1-VPS34 may regulate $\mathrm{c}-\mathrm{Src}$ phosphorylation at $\mathrm{Y} 416$ in RAW264.7 cells (Fig. 8G).

Role of Other sPLA2 Isoforms in Intracellular Translocation of AcLDL and Pgk1 Gene Expression in RAW264.7 Cells

We examined whether other sPLA2 isoforms than sPLA $2-\mathrm{V}$ may have a role in intracellular translocation of AcLDL to lysosomes and PGK1 expression in RAW264.7 cells. First, we measured expression levels 


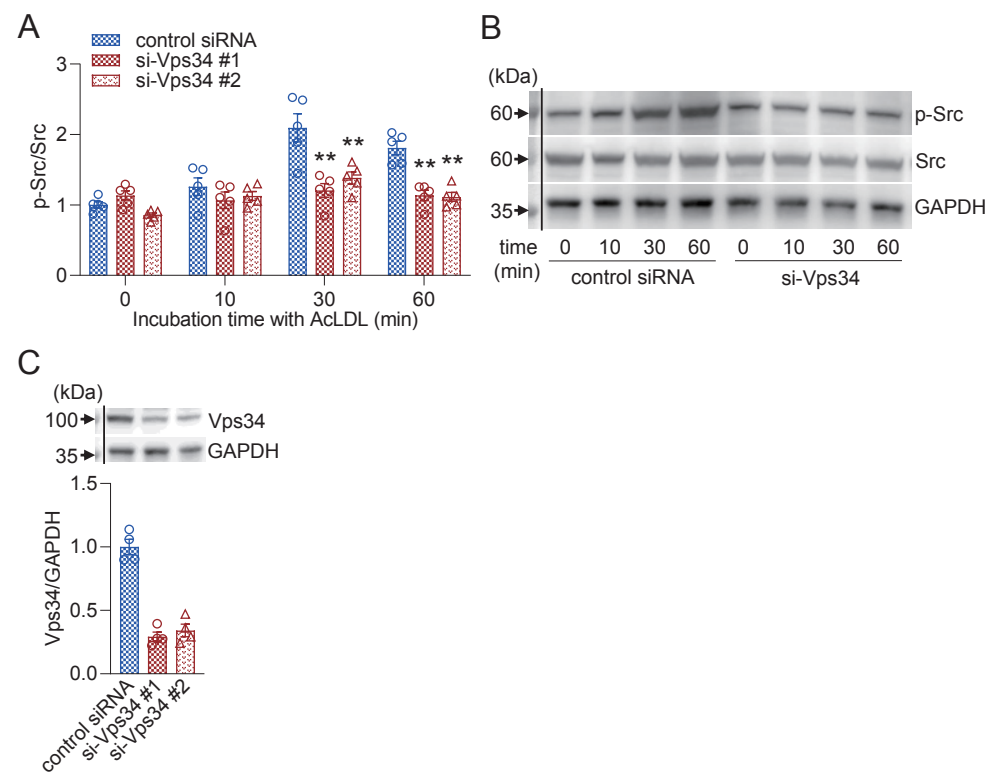

Fig. 10. Role of VPS34 in c-Src phosphorylation

A, siRNA-mediated reduction of VPS34 expression suppressed c-Src phosphorylation at Y416 in response to AcLDL in sPLA2-V WT RAW264.7 cells. Values in panels were normalized to that of control siRNA at baseline (incubation time 0$)(=1) . n=5$ in each experiment, ${ }^{* *}$, $P<0.01$ vs. control siRNA. B, Representative immunoblots for panel A. C, Reduction of VPS34 protein expression by siRNAs (\#1 and \#2). Values were normalized to that of control siRNA $(=1)$. Upper panel shows representative immunoblots.

of all sPLA2s in RAW264.7 cells by quantitative RT-PCR using $0.5 \mu \mathrm{g}$ of total RNA. In this study, we arbitrarily determined the significant expression of mRNA as cycle threshold $(\mathrm{Ct})$ value of each $s \mathrm{PLA}_{2}<\mathrm{Ct}$ value of negative control. The $\mathrm{Ct}$ values of negative control were $>31$. Among sPLA2s, sPLA2-IID $(\mathrm{Ct}=24.7 \pm 0.8),-\mathrm{IIE}(\mathrm{Ct}=23.5 \pm 0.4),-\mathrm{V}(\mathrm{Ct}=22.7 \pm$ $0.1)$, and -XIIA $(\mathrm{Ct}=22.1 \pm 0.1)$ were significantly expressed in RAW264.7 cells on the basis of the $\mathrm{Ct}$ value. Next, we examined whether siRNA-mediated knockdown of sPLA2-IID, IIE, or -XIIA may reduce PGK1 expression and intracellular translocation of pHrodo-conjugated AcLDL to lysosomes in sPLA2-V WT Raw264.7 cells. As shown in Supplementary Fig. 2, knockdown of these sPLA2s had no effects on intracellular translocation of pHrodo-conjugated AcLDL and Pgk1 gene expression in RAW264.7 cells. Thus, other $\mathrm{PPLA}_{2 \mathrm{~s}}$ did not seem to have similar activities as sPLA2-V.

Primary Cultures of Peritoneal Macrophages from sPLA2-V KO Mouse Had an Impairment of Endocytosis of AcLDL and Actin Polymerization and Reduction of PGK1 Expression, Beclin 1 Phosphorylation, and c-Src Phosphorylation

Primary cultures of peritoneal macrophages from sPLA2-V KO mice had impairments in internalization
(Fig. 11A) and degradation of ${ }^{125}$ I AcLDL (Fig. 11B), yet had similar levels of cell-surface-specific binding as compared with peritoneal macrophages from sPLA2-V WT mice (Fig. 11C). Flow cytometry using Alexa Fluor 546-phalloidin showed a lower degree of actin polymerization in response to AcLDL in $s \mathrm{PLA}_{2}-\mathrm{V} \mathrm{KO}$ peritoneal macrophages compared with sPLA2-V WT cells (Fig. 11D). sPLA2-V KO peritoneal macrophages showed a lower magnitude of mean fluorescence intensity (MFI) of pHrodo after incubation with pHrodo-conjugated AcLDL (Fig. 11E). Furthermore, levels of PGK1 expression and Beclin 1 phosphorylation at $S 30$ were reduced in peritoneal macrophages from sPLA2-V KO mice compared with those from sPLA2-V WT mice (Figs. $11 \mathrm{~F}$ and $11 \mathrm{G}$ ). c-Src phosphorylation at Y416 was also decreased in peritoneal macrophages isolated from sPLA2-V KO mice compared to those from sPLA2-V WT mice (Fig. 11H). Representative immunoblots for panels $G$ and $\mathrm{H}$ are shown in Fig. $11 \mathrm{I}$.

\section{Discussion}

The present study is the first to demonstrate that sPLA2-V in the nucleus binds to the promoter region of the Pgk1 gene and increases its transcriptional activity in RAW264.7 cells. Similarly, sPLA2-V- 

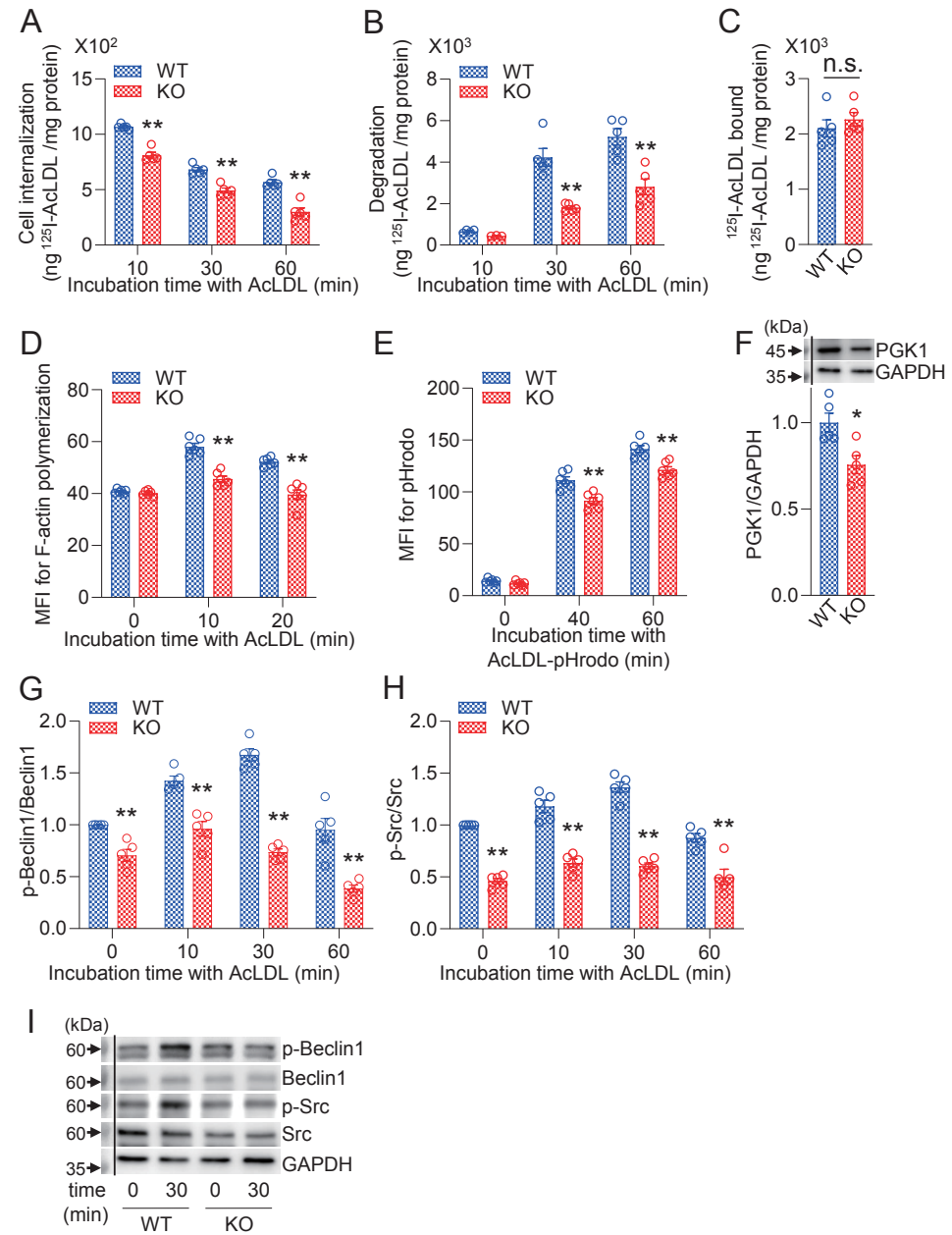

Fig. 11. Experiments using primary cultures of peritoneal macrophages from sPLA2-V WT and knockout (KO) mice

$\mathrm{A}, \mathrm{B}$, and C, sPLA2-V KO peritoneal macrophages had impaired specific internalization (A) and degradation (B) of ${ }^{125}$ I AcLDL but a similar degree of cell surface-specific binding $(C)$ compared to sPLA2-V WT peritoneal macrophages. D and E, sPLA2-V KO peritoneal macrophages had decreased amounts of actin polymerization (D) and translocation of internalized AcLDL conjugated with pHrodo (E) compared with sPLA2-V WT macrophages. F, G, and H, PGK1 expression at baseline (F), Beclin1 phosphorylation at S30 (G), and c-Src phosphorylation at Y416 $(\mathrm{H})$ were decreased in peritoneal macrophages from sPLA2-V KO mice compared with those from sPLA2-V WT mice. Values in panels F, G, and $\mathrm{H}$ were normalized to that of WT (incubation time 0 in panels $\mathrm{G}$ and $\mathrm{H})(=1)$. Each bar represents the mean \pm SEM of 5 independent experiments. *, $P<0.05,{ }^{* *}, P<0.01$ vs. WT. I, Representative immunoblots in panels of $\mathrm{G}$ and $\mathrm{H}$.

H48Q, which lacks enzymatic activity ${ }^{19)}$, also bound and promoted transcriptional activity of the Pgk1 gene. The hydrolytic activity of sPLA2s requires $\mathrm{mM}$ concentrations of $\mathrm{Ca}^{2+1)}$, whereas the calcium concentration in both the nucleus and the cytosol is at most a few $\mu \mathrm{M}^{6}$ ). In the present study, the suppressed expression of PGK1 in sPLA2-V KD RAW264.7 cells could be restored by transfection with sPLA2-VH48Q. Taken together, sPLA2-V could promote Pgk1 gene transcription via a mechanism that does not involve enzymatic activity.

Immunofluorescence microscopic studies showed that immunoreactivity of sPLA2-V and Myc-sPLA $2-\mathrm{V}$, that were re-constitutively expressed, was detected in the nucleus as well as cytoplasmic area of sPLA2-V KD RAW264.7 cells. Also, immunoreactivity of endogenous sPLA2-V was detected in the nucleus as well as cytoplasmic area of primary peritoneal macrophages. In addition, fluorescence microscopy showed nuclear localization of GFP-tagged sPLA2-V in $\mathrm{PPLA}_{2}-\mathrm{V}$ KD RAW264.7 cells. Furthermore, immunoreactivity of $s \mathrm{PLA}_{2}-\mathrm{V}$ or $\mathrm{Myc}-\mathrm{sPLA} 2 \mathrm{~V}$ was detected in the isolated nuclei from sPLA2-V KD RAW264.7 cells with re-constitutive expression of each of them and from sPLA2-V WT peritoneal macrophages, which may support the finding obtained with whole cells. In the immunoblotting, MycsPLA2-V was shown in the nuclear subcellular 
fractions of sPLA2-V KD RAW264.7 cells with expression of Myc-sPLA2-V. These studies showed that extent of expression of sPLA2-V and Myc- or GFPtagged sPLA2-V localized in the nucleus appeared to be very lower than that in the cytoplasmic area. Thus, it may require further evaluation of nuclear localization of sPLA2-V using other methods. According to computational approaches, sPLA2-V has neither DNA binding motifs nor sequence motifs corresponding to either nuclear localization signals or nuclear export signals. The mechanism underlying the nuclear localization of ${ }_{s} P_{L} A_{2}-\mathrm{V}$ is entirely unclear at the present time. sPLA2-V has neither the group I and II sPLA2s -specific the disulfide bridge between cysteines 11 and 77, nor does it contain the 6-amino acid C-terminal extension characteristic of group II ${ }_{s} \mathrm{PLA}_{22}{ }^{25)}$. It is speculated that these structural characteristics of sPLA2-V that are different from those of other sPLA $2 s$ may be involved in the nuclear localization of s $\mathrm{PLA}_{2}-\mathrm{V}$. In addition, since molecular weights of sPLA2-V and GFP-tagged sPLA2-V were approximately $14 \mathrm{kDa}$ and $41 \mathrm{kDa}$, respectively, they are small enough to enter and exist in the nucleus by passive diffusion through nuclear pores ${ }^{26)}$. The Pgk1 gene is constitutively expressed and is ubiquitously present in all somatic cells ${ }^{27,28)}$. The promoter region of Pgk1 gene has multiple binding sites for transcriptional factors and possess constitutive enhance activity ${ }^{27,28)}$. It is fully unclear how the sPLA2-V protein interacts with $P g k 1$ promoter region to enhance the promoter activity. There is a possibility that sPLA2-V may presumably bind to unknown cytosolic proteins which could import to the nucleus, and that the protein complex with sPLA2-V may interact with the promoter region of $P g k 1$ gene so that the transcription of $P g k 1$ gene could proceed.

PGK1 is known to play a key role in the glycolysis pathway. Recently, PGK1 was shown to phosphorylate Beclin1 at the active site (S30) in a manner that is independent of its role in the glycolysis ${ }^{12)}$. This phosphorylation promotes activation of the Beclin1-VPS34 (class III PI3-kinase) complex ${ }^{12)}$. Beclin1 is a core component of this class III PI3-kinase complex, and Beclin 1 phosphorylated at $\mathrm{S} 30$ activates class III PI3-kinase to generate $\mathrm{PI}(3) \mathrm{P}^{14,15)}$. $\mathrm{PI}(3) \mathrm{P}$ in turn interacts with the early endosome antigen 1, Rab5, and Rab7 on the endosomal membrane and contributes to endosomal maturation ${ }^{29)}$. $\mathrm{PI}(3) \mathrm{P}$ is also required for actin polymerization during phagosome formation ${ }^{30)}$. On the basis of the present studies using approach of PGK1 overexpression and siRNA-mediated reduction of PGK1 and Beclin1 expression, PGK1-Beclin1 plays a role in actin polymerization and intracellular trafficking of internalized AcLDL in RAW264.7 cells, and that sPLA2-V regulates AcLDL endocytosis through the PGK1-Beclin1 pathway (Fig.8G). Since actin polymerization has an important role in the early stages of endocytic vesicle internalization and translocation of cargo from early endosomes to late endosome/lysosomes ${ }^{23,24)}$, impairment of actin polymerization might contribute to the reduction of both internalization and intracellular trafficking of Ac-LDL to lysosomes in sPLA2-V deficient cells. Previous clinical report described that PGK1 deficiency was associated with hemolytic anemia, rhabdomyolysis, and/or mental retardation ${ }^{31)}$. It remains unclear whether the present findings may have a role in the pathogenesis of these disorders in humans.

The results of this study suggested that c-Src plays a regulatory role in $\mathrm{sPLA}_{2}-\mathrm{V}$ - mediated internalization and intracellular trafficking of AcLDL to lysosomes in RAW264.7 cells. The Src family of protein tyrosine kinases is known to play key roles in receptor-mediated endocytosis and endosomal maturation via actin polymerization ${ }^{32)}$. Suppressed expression of Beclin1 was previously shown to reduce c-Src phosphorylation at Y416 (the active site) ${ }^{33,34)}$. In agreement with these earlier findings ${ }^{33,34)}$, results of the present study showed that siRNA-mediated suppression of PGK1, Beclin1, or VPS34 inhibited c-Src phosphorylation at Y416. Thus, PGK1-Beclin1VPS34 may play a role in c-Src activation in RAW264.7 cells (Fig. 8G).

The findings obtained here support an important role of sPLA2-V in actin polymerization and endocytosis of AcLDL in primary cultures of mouse peritoneal macrophages. In addition, sPLA2-V KO peritoneal macrophages had reductions in PGK1 expression, Beclin1 phosphorylation, and c-Src phosphorylation that were similar to those seen in

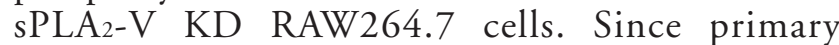
macrophage cultures are difficult to be transfected with siRNA or cDNA constructs ${ }^{18)}$, the details of mechanisms associated with sPLA2-V could not be defined. Nevertheless, similar mechanisms as those seen for RAW264.7 cells, a mouse monocyte/ macrophage cell line, might be extended to explain the results obtained for peritoneal macrophages. Balestrieri et al. showed an impairment of endocytosis and intracellular trafficking of zymosan and Candida albicans after binding to their cell-surface receptor, dectin-1 and/or Toll-like receptors, in sPLA2-V KO murine macrophages in a manner that was independent of its enzymatic activity ${ }^{9,10)}$. In this context, the impairment of endocytosis and intracellular trafficking was shown in other ligandreceptor systems in $s \mathrm{PLA}_{2}-\mathrm{V} \mathrm{KO}$ macrophages in a 
similar manner as observed in the present study. In addition, they showed that mice lacking sPLA $2-\mathrm{V}$ had an increased fungal burden in the kidney, liver, and spleen in an in vivo model of systemic candidiasis ${ }^{10)}$. Thus, the findings at the cellular level were extended to those in an in vivo animal model. However, it remains unknown whether a decrease in PGK1 expression mediated by $\mathrm{sPLA}_{2}-\mathrm{V}$ deficiency may be involved in the mechanisms for the impairments of endocytosis and intracellular trafficking of zymosan and Candida albicans in in vitro macrophages and in vivo mice model.

It cannot be fully ruled out that enzymatic activity of sPLA2-V may be required for phagocytosis of microorganisms in macrophages. In human macrophages, ethanolamine lysophospholipid generated via sPLA2-V-mediated hydrolysis of membrane ethanolamine contributed to phagocytosis of microorganisms ${ }^{35)}$. Moreover, studies using sPLA2$\mathrm{V}$-deficient mice have revealed that $s \mathrm{PLA}_{2}-\mathrm{V}$-driven release of oleic and linoleic acids is crucial for polarization into M2-like macrophages, which have a greater phagocytic potential than M1-like macrophages ${ }^{36,37)}$, although the functions of M1 and M2 macrophages are context-specific.

It is unclear whether sPLA2-V-mediated endocytosis of modified LDL in macrophages has a beneficial or detrimental effect in atherosclerotic plaque progression and stability. Uptake of modified LDL protects macrophages against cytotoxicity of modified LDL but results in foam cell formation and plaque progression ${ }^{38)}$. Although macrophage endocytosis/phagocytosis is necessary to remove proinflammatory apoptotic cells, strong proatherogenic properties are elicited upon endocytosis/phagocytosis of modified lipoproteins, erythrocytes and platelets ${ }^{38)}$. Bostrom and his coworkers previously showed that sPLA2-V KO macrophages had less atherogenicity in LDL receptor-deficient mice ${ }^{39)}$. In this regard, $\mathrm{SPLA}_{2}-$ $\mathrm{V}$-mediated endocytosis of modified LDL by macrophages may be proatherogenic. It remains to be defined whether cholesterol ester accumulation induced by Ac-LDL may be decreased in sPLA2-V KD RAW264.7 cells. If the decrease occurs, it will be required to be determined whether the decrease in cholesterol ester accumulation may be restored by ${ }_{s} \mathrm{PLA}_{2}-\mathrm{V}$ re-constitutive expression.

PGK1 translocates to mitochondria in response to hypoxic conditions and inhibits the pyruvate dehydrogenase complex, which in turn suppresses mitochondrial oxidative phosphorylation of pyruvate ${ }^{40)}$. Thus, PGK1 could promote the Warburg effects in the lesion macrophages in the hypoxic milieu such as that found in thickened arterial walls with highly advanced atherosclerosis. sPLA2-V plays a role in the inflammatory innate immune response in macrophages as previously described ${ }^{9,}{ }^{10)}$. In this context, coordination of sPLA2-V and PGK1 might link the inflammatory innate immune response and changes in glucose metabolism in the lesion macrophages, thus providing a novel mechanism for immunometabolism ${ }^{41,42)}$.

In conclusion, $\mathrm{PPLA}_{2}-\mathrm{V}$ in the nucleus of RAW264.7 cells binds to the promoter region of the Pgk1 gene and increases its transcriptional activity. ${ }_{s P L A}-V$ regulates endocytosis of AcLDL through PGK1-Beclin1 in a manner that is independent of its enzymatic activity. Although a non-enzymatic action of $s \mathrm{PLA}_{2}$ through the $s \mathrm{PLA}_{2}$ receptor on the plasma membrane has been demonstrated in previous studies ${ }^{43,44)}$, the present study provides a novel functional role for $s P L A_{2}-\mathrm{V}$ as a transcriptional regulator in the nucleus.

\section{Funding}

This work was supported by AMED-CREST (JP17gm0710006), and JSPS KAKENHI Grant Number B2-19390209 and B-22390158.

\section{Conflict of Interest}

Kiyotaka Kugiyama has received scholarship donations from Takeda, Daiichi Sankyo, Astellas, Boehringer Ingelheim, MSD, Boston Scientific Japan, Abbott, Medtronic, Biotronik Japan, and St Jude Medical. The remaining authors declare no conflicts of interest.

\section{Author Contribution}

DF and KK contributed to design, analysis and interpretation of data and drafted the paper. YW performed experiments. TY, TN, MM and KM designed and supervised the study.

\section{References}

1) Murakami M, Sato H, Miki Y, Yamamoto K, Taketomi $Y$ : A new era of secreted phospholipase A2. J Lipid Res, 2015; 56: 1248-1261

2) Bingham CO 3rd, Fijneman RJ, Friend DS, Goddeau RP, Rogers RA, Austen KF, Arm JP: Low molecular weight group IIA and group $\mathrm{V}$ phospholipase $\mathrm{A}(2)$ enzymes have different intracellular locations in mouse bone marrowderived mast cells. J Biol Chem, 1999; 274: 31476-31484

3) Nardicchi V, Macchioni L, Ferrini M, Goracci G: The presence of a secretory phospholipase A2 in the nuclei of neuronal and glial cells of rat brain cortex. Biochim 
Biophys Acta, 2007; 1771: 1345-1352

4) Fayard JM, Tessier C, Pageaux JF, Lagarde M, Laugier C: Nuclear location of PLA2-I in proliferative cells. J Cell Sci, 1998; 111 (Pt 7): 985-994

5) Oishi T, Tamiya-Koizumi K, Kudo I, Iino S, Takagi K, Yoshida S: Purification and characterization of nuclear alkaline phospholipase A2 in rat ascites hepatoma cells. FEBS Lett, 1996; 394: 55-60

6) Birch BD, Eng DL, Kocsis JD: Intranuclear Ca2+ transients during neurite regeneration of an adult mammalian neuron. Proc Natl Acad Sci U S A, 1992; 89: 7978-7982

7) Brown WJ, Chambers K, Doody A: Phospholipase A2 (PLA2) enzymes in membrane trafficking: mediators of membrane shape and function. Traffic, 2003; 4: 214-221

8) Underhill DM, Ozinsky A: Phagocytosis of microbes: complexity in action. Annu Rev Immunol, 2002; 20: 825-852

9) Balestrieri B, Hsu VW, Gilbert H, Leslie CC, Han WK, Bonventre JV, Arm JP: Group V secretory phospholipase A2 translocates to the phagosome after zymosan stimulation of mouse peritoneal macrophages and regulates phagocytosis. J Biol Chem, 2006; 281: 66916698

10) Balestrieri B, Maekawa A, Xing W, Gelb MH, Katz HR, Arm JP: Group V secretory phospholipase A2 modulates phagosome maturation and regulates the innate immune response against Candida albicans. J Immunol, 2009; 182: 4891-4898

11) Zhu XD, Zhuang Y, Ben JJ, Qian LL, Huang HP, Bai H, Sha JH, He ZG, Chen Q: Caveolae-dependent endocytosis is required for class A macrophage scavenger receptor-mediated apoptosis in macrophages. J Biol Chem, 2011; 286: 8231-8239

12) Qian X, Li X, Cai Q, Zhang C, Yu Q, Jiang Y, Lee JH, Hawke D, Wang Y, Xia Y, Zheng Y, Jiang BH, Liu DX, Jiang T, Lu Z: Phosphoglycerate kinase 1 phosphorylates Beclin1 to induce autophagy. Mol Cell, 2017; 65: $917-$ 931.e6

13) Li X, Zheng Y, Lu Z: PGK1 is a new member of the protein kinome. Cell Cycle, 2016; 15: 1803-1804

14) Funderburk SF, Wang QJ, Yue Z: The Beclin 1-VPS34 complex--at the crossroads of autophagy and beyond. Trends Cell Biol, 2010; 20: 355-362

15) Wirawan E, Lippens $S$, Vanden Berghe T, Romagnoli A, Fimia GM, Piacentini M, Vandenabeele P: Beclin1: a role in membrane dynamics and beyond. Autophagy, 2012; 8: 6-17

16) Yano T, Fujioka D, Saito Y, Kobayashi T, Nakamura T, Obata JE, Kawabata K, Watanabe K, Watanabe Y, Mishina H, Tamaru S, Kugiyama K: Group V secretory phospholipase A2 plays a pathogenic role in myocardial ischaemia-reperfusion injury. Cardiovasc Res, 2011; 90: 335-343

17) Watanabe K, Watanabe K, Watanabe Y, Fujioka D, Nakamura T, Nakamura K, Obata JE, Kugiyama K: Human soluble phospholipase A2 receptor is an inhibitor of the integrin-mediated cell migratory response to collagen-I. Am J Physiol Cell Physiol, 2018; 315: C398-C408

18) Horwood NJ, Smith C, Andreakos E, Quattrocchi E,
Brennan FM, Feldmann M, Foxwell BM: High-efficiency gene transfer into nontransformed cells: utility for studying gene regulation and analysis of potential therapeutic targets. Arthritis Res, 2002; 4 Suppl 3 (Suppl 3): $\$ 215-225$

19) Chioato L, Aragão EA, Ferreira TL, Ward RJ: Active site mutants of human secreted Group IIA Phospholipase A2 lacking hydrolytic activity retain their bactericidal effect. Biochimie, 2012; 94: 132-136

20) Yokoyama $T$, Nakatake $M$, Kuwata $T$, Couzinet $A$, Goitsuka R, Tsutsumi S, Aburatani H, Valk PJ, Delwel R, Nakamura T: MEIS1-mediated transactivation of synaptotagmin-like 1 promotes CXCL12/CXCR4 signaling and leukemogenesis. J Clin Invest, 2016; 126: 1664-1678

21) Dunn WA, Hubbard AL, Aronson NN Jr: Low temperature selectively inhibits fusion between pinocytic vesicles and lysosomes during heterophagy of 125I-asialofetuin by the perfused rat liver. J Biol Chem, 1980; 255: 5971-5978

22) Miller YI, Worrall DS, Funk CD, Feramisco JR, Witztum JL: Actin polymerization in macrophages in response to oxidized LDL and apoptotic cells: role of 12/15-lipoxygenase and phosphoinositide 3-kinase. Mol Biol Cell, 2003; 14: 4196-4206

23) Girao H, Geli MI, Idrissi FZ: Actin in the endocytic pathway: from yeast to mammals. FEBS Lett, 2008; 582: 2112-2119

24) Castellano F, Chavrier P, Caron E: Actin dynamics during phagocytosis. Semin Immunol, 2001; 13: 347-355

25) Chen J, Engle SJ, Seilhamer JJ, Tischfield JA: Cloning and recombinant expression of a novel human low molecular weight $\mathrm{Ca}(2+)$-dependent phospholipase A2. J Biol Chem, 1994; 269: 2365-2368

26) Görlich D, Kutay U: Transport between the cell nucleus and the cytoplasm. Annu Rev Cell Dev Biol, 1999; 15: 607-660

27) Sutherland LC, St-Arnaud R, McBurney MW: An upstream activator sequence regulates the murine Pgk-1 promoter and binds multiple nuclear proteins. Gene Expr, 1995; 4: 265-279

28) McBurney MW, Sutherland LC, Adra CN, Leclair B, Rudnicki MA, Jardine K: The mouse Pgk-1 gene promoter contains an upstream activator sequence. Nucleic Acids Res, 1991; 19: 5755-5761

29) Lindmo K, Stenmark H: Regulation of membrane traffic by phosphoinositide 3-kinases. J Cell Sci, 2006; 119: 605-614

30) Bohdanowicz M, Cosío G, Backer JM, Grinstein S: Class I and class III phosphoinositide 3-kinases are required for actin polymerization that propels phagosomes. J Cell Biol, 2010; 191: 999-1012

31) Beutler E: PGK deficiency. Br J Haematol, 2007; 136: 3-11

32) Sandilands E, Frame MC: Endosomal trafficking of Src tyrosine kinase. Trends Cell Biol, 2008; 18: 322-329

33) Pang $M$, Wang H, Rao P, Zhao Y, Xie J, Cao Q, Wang $Y$, Wang YM, Lee VW, Alexander SI, Harris DC, Zheng G: Autophagy links $\beta$-catenin and Smad signaling to promote epithelial-mesenchymal transition via upregulation of integrin linked kinase. Int J Biochem Cell 
Biol, 2016; 76: 123-134

34) Hamurcu Z, Delibaşı N, Geçene S, Şener EF, DönmezAltuntaş H, Özkul Y, Canatan H, Ozpolat B: Targeting LC3 and Beclin-1 autophagy genes suppresses proliferation, survival, migration and invasion by inhibition of Cyclin-D1 and uPAR/Integrin $\beta 1 /$ Src signaling in triple negative breast cancer cells. J Cancer Res Clin Oncol, 2018; 144: 415-430

35) Rubio JM, Rodríguez JP, Gil-de-Gómez L, Guijas C, Balboa MA, Balsinde J: Group V secreted phospholipase A2 is upregulated by IL- 4 in human macrophages and mediates phagocytosis via hydrolysis of ethanolamine phospholipids. J Immunol, 2015; 194: 3327-3339

36) Sato $H$, Taketomi $Y$, Ushida A, Isogai $Y$, Kojima T, Hirabayashi T, Miki Y, Yamamoto K, Nishito Y, Kobayashi T, Ikeda K, Taguchi R, Hara S, Ida S, Miyamoto Y, Watanabe M, Baba H, Miyata K, Oike Y, Gelb MH, Murakami M: The adipocyte-inducible secreted phospholipases PLA2G5 and PLA2G2E play distinct roles in obesity. Cell Metab, 2014; 20: 119-132

37) Yamaguchi M, Samuchiwal SK, Quehenberger O, Boyce JA, Balestrieri B: Macrophages regulate lung ILC2 activation via Pla2g5-dependent mechanisms. Mucosal Immunol, 2018; 11: 615-626

38) Schrijvers DM, De Meyer GR, Herman AG, Martinet W: Phagocytosis in atherosclerosis: Molecular mechanisms and implications for plaque progression and stability.
Cardiovasc Res, 2007; 73: 470-480

39) Bostrom MA, Boyanovsky BB, Jordan CT, Wadsworth MP, Taatjes DJ, de Beer FC, Webb NR: Group v secretory phospholipase A2 promotes atherosclerosis: evidence from genetically altered mice. Arterioscler Thromb Vasc Biol, 2007; 27: 600-606

40) Li X, Jiang Y, Meisenhelder J, Yang W, Hawke DH, Zheng Y, Xia Y, Aldape K, He J, Hunter T, Wang L, Lu Z: Mitochondria-Translocated PGK1 functions as a protein kinase to coordinate glycolysis and the TCA Cycle in tumorigenesis. Mol Cell, 2016; 61: 705-719

41) Tabas I, Bornfeldt KE: Intracellular and intercellular aspects of macrophage immunometabolism in atherosclerosis. Circ Res, 2020; 126: 1209-1227

42) Van den Bossche J, O’Neill LA, Menon D: Macrophage Immunometabolism: Where Are We (Going)? Trends Immunol, 2017; 38: 395-406

43) Lambeau G, Lazdunski M: Receptors for a growing family of secreted phospholipases A2. Trends Pharmacol Sci, 1999; 20: 162-170

44) Mishina H, Watanabe K, Tamaru S, Watanabe $Y$, Fujioka D, Takahashi S, Suzuki K, Nakamura T, Obata JE, Kawabata K, Yokota Y, Inoue O, Murakami M, Hanasaki K, Kugiyama K: Lack of phospholipase A2 receptor increases susceptibility to cardiac rupture after myocardial infarction. Circ Res, 2014; 114: 493-504 
Supplementary Table 1. Oligonucleotide sequences for qPCR, siRNA, and mutagenesis

\begin{tabular}{|c|c|c|c|}
\hline qPCR primers & sense & antisense & cat. no. \\
\hline Pla2g1b & $5^{\prime}$-cga ctt aga cag gtg ctg cca g- $3^{\prime}$ & $5^{\prime}$-ggc gct gca ggt gat ctc g-3' & \\
\hline Pla $2 g 2 a$ & $5^{\prime}$-cct ttg gct caa tac agg tcc- $3^{\prime}$ & $5^{\prime}$-gtc atg agt aac aca gca ccg gtc- $3^{\prime}$ & \\
\hline Pla2g2c & $5^{\prime}$-cct tgt ctt cat ctt cta ctg gac- $3^{\prime}$ & $5^{\prime}-\operatorname{ccc}$ agc agc acc tgt ctg tg- $3^{\prime}$ & \\
\hline Pla2g2d & $5^{\prime}$-cag act ggt gct gtc aga agc-3' & $5^{\prime}$-ctc ccg ttg tca gag cac tg-3' & \\
\hline Pla2g2e & $5^{\prime}-\mathrm{ctt} \operatorname{tgc} \mathrm{ctc} \operatorname{ctg}$ gtg ccc ctg- $3^{\prime}$ & $5^{\prime}-$ gac aac acc aat ccg tct cg-3' & \\
\hline Pla2g2f & $5^{\prime}$-gac tgg tgc tgc cat gcc cac- $3^{\prime}$ & $5^{\prime}$-ctc att gag ctc agt gca gac- $3^{\prime}$ & \\
\hline Pla2g3 & $5^{\prime}$-gtg acg cca ggt ttc aac ag- $3^{\prime}$ & $5^{\prime}-\operatorname{gcc} \operatorname{ctg} \mathrm{cac} \operatorname{ccg} \operatorname{ccc} \mathrm{cac} c-3^{\prime}$ & \\
\hline Pla2g5 & $5^{\prime}$-gac cgt tgt tat ggg caa- $3^{\prime}$ & $5^{\prime}$-agg agt cgt gtt cgc aga tga- $3^{\prime}$ & \\
\hline Pla2g10 & $5^{\prime}$-cag cga agc aac cag gag- $3^{\prime}$ & $5^{\prime}$-gta gca gca cca gtc aat ggc-3' & \\
\hline Pla2g12a & $5^{\prime}$-gtg cag cga cgg atc gaa gc- $3^{\prime}$ & $5^{\prime}$-gga agg gat acc tat gtt cag atg-3' & \\
\hline Pla2g12b & $5^{\prime}$-gtc gat atg gaa agg cgc cg-3' & $5^{\prime}$-ggt cca tac ttc ctg gta cct tg- $3^{\prime}$ & \\
\hline $\operatorname{Src}$ & $5^{\prime}$-ggc tga gga gtg gta ctt tgg- $3^{\prime}$ & $5^{\prime}$-cag aga ggc agt agg cac ctt ttg-3 & \\
\hline Gapdh & $5^{\prime}-\operatorname{tgc}$ acc acc aac tgc tta g- $3^{\prime}$ & $5^{\prime}$-gat gca ggg atg atg ttc- $3^{\prime}$ & \\
\hline Pgk1 & $5^{\prime}$-aaa caa ggt taa agc tga gcc g- $3^{\prime}$ & $5^{\prime}$-ttc aca ccc acc atg gag cta $\mathrm{t}-3^{\prime}$ & \\
\hline Becn1 & $5^{\prime}$-gac tca agg tca ctg gag- $3^{\prime}$ & $5^{\prime}-\mathrm{cca}$ aac agc gtt tgt agt- $3^{\prime}$ & \\
\hline ChIP-binding site & $5^{\prime}$-cag gac gtg aca aat gga agt- $3^{\prime}$ & $5^{\prime}$-cag aaa gcg aag gag caa ag-3' & \\
\hline ChIP-unrelated site & $5^{\prime}$-aag tgc tgg gat taa agg cg-3 & $5^{\prime}$-tca aag ggg aaa cta tgc aaa ca-3' & \\
\hline \multicolumn{4}{|l|}{ siRNA } \\
\hline Pla2g2d \#1 & \multicolumn{2}{|l|}{$5^{\prime}-$ cag acu ggu gcu guc aga a-3' } & SASI_Mm01_00195778 \\
\hline Pla2g2d \#2 & \multicolumn{2}{|l|}{$5^{\prime}$-ccu uca aac ucu ggu cuu u- $3^{\prime}$} & SASI_Mm01_00195777 \\
\hline Pla2g2e \#1 & \multicolumn{2}{|l|}{$5^{\prime}$-ccc ugc agu aca aug acu a-3' } & SASI_Mm01_00059877 \\
\hline Pla2g2e \#2 & \multicolumn{2}{|l|}{$5^{\prime}$-gcg gga acc ugg ucc agu u-3' } & SASI_Mm01_00059876 \\
\hline Pla2g12a \#1 & \multicolumn{2}{|l|}{$5^{\prime}-\mathrm{ccu}$ aau guu gcc uua guu u- $3^{\prime}$} & SASI_Mm02_00326922 \\
\hline Pla2g12a \#2 & \multicolumn{2}{|l|}{$5^{\prime}$-cau uua ggc ugc aag cca u-3' } & SASI_Mm01_00175576 \\
\hline Pgk1 \#1 & \multicolumn{2}{|l|}{$5^{\prime}$-cag aca aga ucc agc uga $u-3^{\prime}$} & SASI_Mm01_00039220 \\
\hline Pgk1 \#2 & \multicolumn{2}{|l|}{$5^{\prime}$-gug uga auc ugc cac aga a- $3^{\prime}$} & SASI_Mm01_00039219 \\
\hline Becn 1 \#1 & \multicolumn{2}{|l|}{$5^{\prime}$-cug aga aug aau guc aga a-3' } & SASI_Mm01_00048143 \\
\hline Becn1 \#2 & \multicolumn{2}{|l|}{$5^{\prime}$-gaa aga ugc uuu aaa uua a-3' } & SASI_Mm01_00048145 \\
\hline Pik3c3 \#1 & \multicolumn{2}{|l|}{$5^{\prime}$-cua caa ggc guu uag uac a-3' } & SASI_Mm01_00099415 \\
\hline Pik3c3 \#2 & \multicolumn{2}{|l|}{$5^{\prime}$-cau cug acc acg auc uca a-3' } & SASI_Mm01_00099414 \\
\hline \multicolumn{4}{|l|}{ mutagenesis primers } \\
\hline avoidance of shRNA 1st & \multicolumn{3}{|c|}{$5^{\prime}$-ctg gag gaa aaa gac tgt gcc att cgg act caa agt tac gat tac aga tac aca aat ggc cta gtc atc tg-3' } \\
\hline avoidance of shRNA 2nd & \multicolumn{3}{|c|}{$5^{\prime}$-act gtg cca ttc gga ctc aaa gtt acg att ata ggt ata cga atg gcc tag tca tct g-3' } \\
\hline Myc deletion & \multicolumn{3}{|c|}{$5^{\prime}$-caa ctt cct ctg cta aac gcg tac gcg gc-3' } \\
\hline H48Q & \multicolumn{3}{|c|}{$5^{\prime}$-gtg ctg tca gat gca gga ccg ttg tta tgg g- $3^{\prime}$} \\
\hline
\end{tabular}

Pre-designed siRNAs were obtained from Sigma. Pik3c3 corresponds to vacuolar protein sorting 34 (VPS34). 

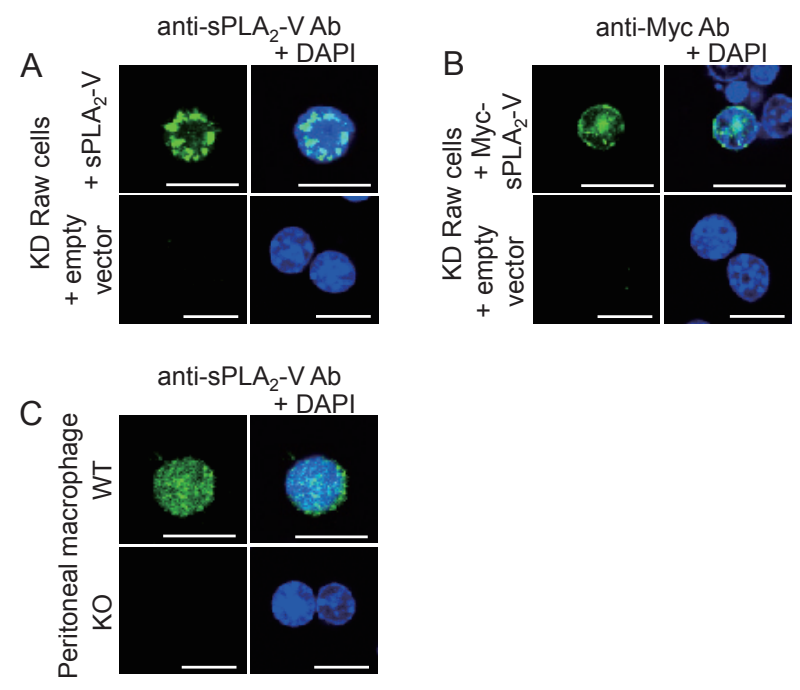
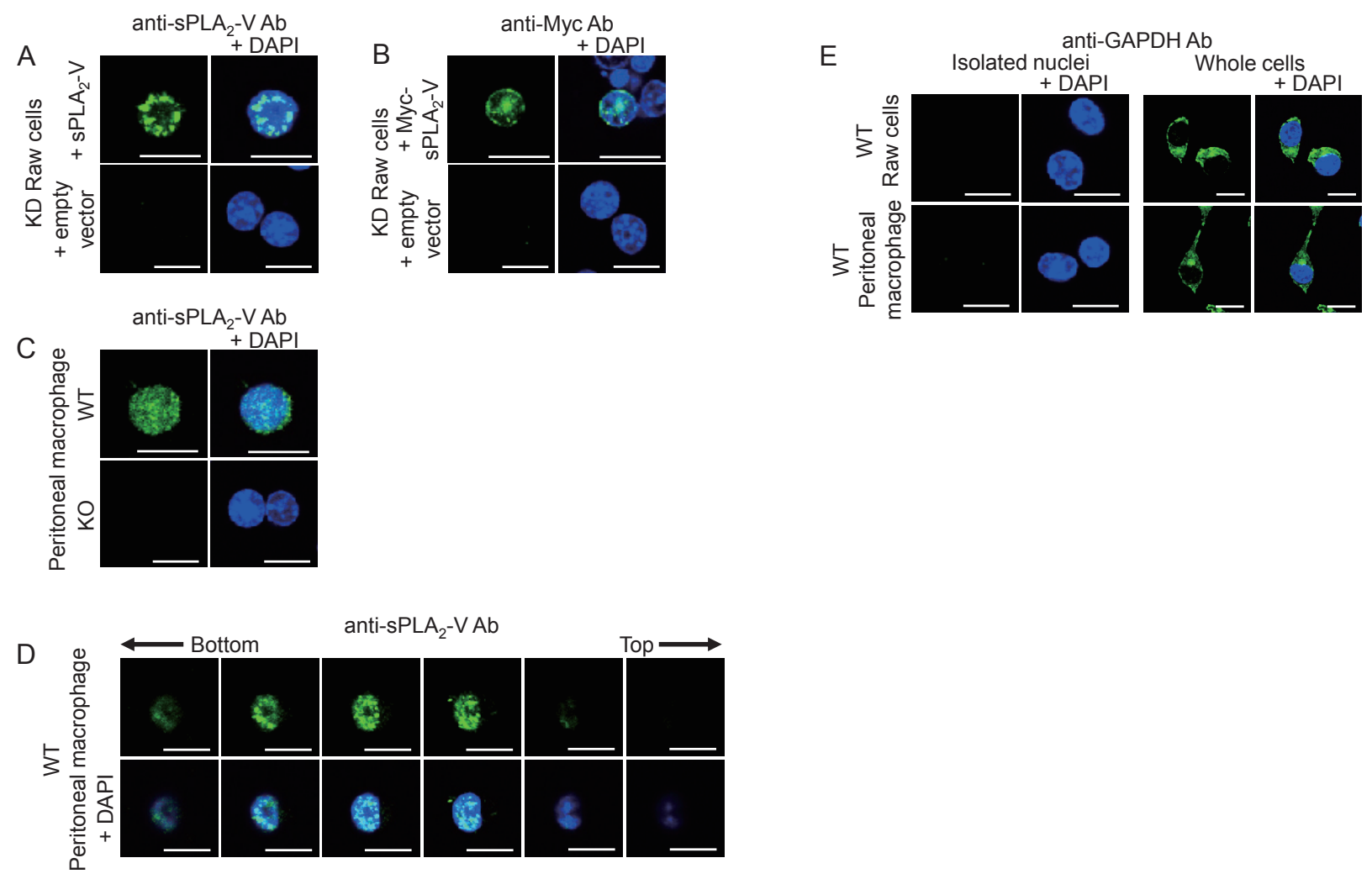

Supplementary Fig. 1. Immunofluorescence Microscopic Study of the Isolated Nuclei

Nuclei were visualized with $4^{\prime}$,6-diamidino-2-phenylindole (DAPI) (blue). Scale bars were $10 \mu \mathrm{m}$. Images of the nucleus (A, B, C, and E) were taken consecutively with $1 \mu \mathrm{m}$ intervals from the bottom edge to the top edge of the nucleus. Among them, the single image that represents the most center of the nucleus was shown. A and B, Immunoreactivity (green) of sPLA2-V and Myc-sPLA2-V was detected in the nuclei isolated from sPLA2-V KD RAW264.7 cells with re-constitutive expression of sPLA2-V and Myc-sPLA2-V, respectively. No immunoreactivity was detected in the nuclei isolated from sPLA2-V KD RAW264.7 cells transfected with empty vector (lower panels). C, Immunoreactivity of endogenous $s \mathrm{PLA}_{2}-\mathrm{V}$ was detected in the nuclei isolated from primary peritoneal macrophages of $s \mathrm{PLA} 2-\mathrm{V}$ wild-type (WT) mice but not from sPLA2-V knockout $(\mathrm{KO})$ mice. D, In the nuclei isolated from peritoneal macrophages of sPLA2-V WT mice, confocal microscopic images were taken consecutively at $1 \mu \mathrm{m}$ intervals from the bottom edge to the top edge of the nucleus. E, The immunoreactivity (green) of GAPDH (cytoplasmic marker) was not detected in the isolated nuclei, suggesting little contamination by cytosolic proteins during procedure of nucleus isolation. 
Supplementary Table 2. ChIP-Seq peak annotations (genome build mouse NCBI38/mm10)

The table below contains ChIP-Seq peak annotations. ChIP-Seq peaks were called using the MACS2 algorithm with a $P$ value of $<0.05$, then annotated using ChIPseeker. The input sample was used by MACS and PeakSeq as a negative control when scoring significant peaks.

\begin{tabular}{|c|c|c|c|c|c|c|c|c|c|c|c|c|}
\hline & $\mathrm{chr}$ & start & end & width & length & $\begin{array}{l}\text { abs_ } \\
\text { summit }\end{array}$ & pileup ( & $\begin{array}{l}(-) \log 10 \\
\text { (pvalue) }\end{array}$ & $\begin{array}{l}\text { fold_ } \\
\text { enrichment }\end{array}$ & $\begin{array}{l}(-) \log 10 \\
\text { (qvalue) }\end{array}$ & $\begin{array}{l}\text { MACS_ } \\
\text { peakID }\end{array}$ & annotation \\
\hline \multirow{8}{*}{$\begin{array}{l}\text { sPLA2-V-KD } \\
\text { cells } \\
\text { transfected } \\
\text { with empty } \\
\text { vector }\end{array}$} & $\operatorname{chr} 12$ & 92171574 & $4 \quad 92171842$ & 269 & 270 & 92171739 & 37 & 18.95476 & 5.86261 & \multicolumn{2}{|c|}{12.65206 sh_peak_1 } & Distal Intergenic \\
\hline & $\operatorname{chr} 13$ & 96359708 & $8 \quad 96359959$ & 252 & 253 & 96359829 & 60 & 23.54721 & 4.80526 & \multicolumn{2}{|c|}{17.15166 sh_peak_2 } & Distal Intergenic \\
\hline & $\operatorname{chr} 14$ & 19416996 & $6 \quad 19417280$ & 285 & 286 & $\quad 19417111$ & 1455 & 159.612 & 2.22361 & \multicolumn{2}{|c|}{152.00955 sh_peak_3 } & Exon (ENSMUST00000177817.1/ENSMUST00000177817.1, exon 3 of 6) \\
\hline & $\operatorname{chr} 3$ & 120717168 & 8120717496 & 329 & 330 & 120717348 & 32 & 15.26837 & 5.2389 & \multicolumn{2}{|c|}{9.11603 sh_peak_4 } & Intron (ENSMUST00000182124.7/320739, intron 3 of 11) \\
\hline & chr 4 & 43301599 & 9 43301966 & 368 & 369 & 43301792 & 70 & 27.75038 & 4.95155 & \multicolumn{2}{|c|}{21.15615 sh_peak_5 } & Intron (ENSMUST00000056010.12/320571, intron 3 of 14) \\
\hline & $\operatorname{chr} 5$ & 103128756 & 6103129013 & 258 & 259 & 103128875 & 11 & 7.44066 & 4.97174 & \multicolumn{2}{|c|}{1.70774 sh_peak_6 } & Intron (ENSMUST00000170792.7/26414, intron 2 of 13) \\
\hline & chr8 & 80640602 & 280640904 & 303 & 304 & 80640747 & 101 & 27.30578 & 3.61368 & \multicolumn{2}{|c|}{20.79199 sh_peak_7 } & Intron (ENSMUST00000039695.6/333315, intron 2 of 7) \\
\hline & chr8 & 81323038 & $8 \quad 81323482$ & 445 & 446 & 81323351 & 13 & 9.4069 & 5.80037 & \multicolumn{2}{|c|}{3.45964 sh_peak_8 } & Distal Intergenic \\
\hline \multirow{10}{*}{$\begin{array}{l}\text { sPLA2-V-KD } \\
\text { cells with } \\
\text { re-constitutive } \\
\text { expression of } \\
\text { sPLA2-V }\end{array}$} & $\operatorname{chr} 12$ & 92171593 & 392171852 & 260 & 261 & 92171703 & 31 & 16.94655 & 6.03379 & \multicolumn{2}{|c|}{10.8227 wt_peak_1 } & Distal Intergenic \\
\hline & $\operatorname{chr} 13$ & 96359691 & 196359981 & 291 & 292 & 96359831 & 60 & 28.88772 & 5.99171 & \multicolumn{2}{|c|}{22.46051 wt_peak_2 } & Distal Intergenic \\
\hline & $\operatorname{chr} 14$ & 19417027 & $7 \quad 19417274$ & 248 & 249 & 19417264 & $4 \quad 1117$ & 29.237 & 1.4298 & \multicolumn{2}{|c|}{22.80464 wt_peak_3 } & Exon (ENSMUST00000177817.1/ENSMUST00000177817.1, exon 3 of 6) \\
\hline & $\operatorname{chr} 15$ & 57420094 & $4 \quad 57420331$ & 238 & 239 & 57420244 & 68 & 18.52421 & 3.51174 & \multicolumn{2}{|c|}{12.35242 wt_peak_4 } & Intron (ENSMUST00000110196.7/210463, intron 2 of 11) \\
\hline & $\operatorname{chr} 2$ & 98666875 & 598667190 & 316 & 317 & 798666930 & 11913 & 9.48874 & 1.05873 & \multicolumn{2}{|c|}{3.59034 wt_peak_5 } & Exon (ENSMUST00000099683.1/ENSMUST00000099683.1, exon 2 of 5) \\
\hline & $\operatorname{chr} 3$ & 120717159 & 9 120717502 & 344 & 345 & 120717346 & 25 & 12.24365 & 5.03874 & \multicolumn{2}{|c|}{6.21642 wt_peak_6 } & Intron (ENSMUST00000182124.7/320739, intron 3 of 11) \\
\hline & chr4 & 43301610 & $0 \quad 43301951$ & 342 & 343 & 43301772 & 50 & 18.62029 & 4.44569 & \multicolumn{2}{|c|}{12.41578 wt_peak_7 } & Intron (ENSMUST00000056010.12/320571, intron 3 of 14) \\
\hline & chr8 & 19762394 & $4 \quad 19762647$ & 254 & 255 & 19762607 & 12 & 9.48963 & 6.06022 & \multicolumn{2}{|c|}{3.59034 wt_peak_8 } & Distal Intergenic \\
\hline & chr8 & 80640580 & 080640923 & 344 & 345 & 80640748 & 111 & 42.54018 & 5.00583 & \multirow{2}{*}{\multicolumn{2}{|c|}{$\begin{array}{c}35.93259 \text { wt_peak_9 } \\
1038.98657 \text { wt_peak_10 }\end{array}$}} & Intron (ENSMUST00000039695.6/333315, intron 2 of 7) \\
\hline & $\operatorname{chr} X$ & 106186725 & 5106187105 & 381 & 382 & 106186926 & 477 & 1047.27539 & 222.82965 & & & Promoter $(<=1 \mathrm{~kb})$ \\
\hline \multirow{20}{*}{$\begin{array}{l}\text { sPLA2-V-KD } \\
\text { cells with } \\
\text { expression of } \\
\text { sPLA2-V- } \\
\text { H48Q }\end{array}$} & $\operatorname{chr} 13$ & 96359683 & 396359972 & 290 & 291 & 96359815 & 30 & 18.28156 & 6.78336 & \multicolumn{2}{|c|}{12.24 h48q_peak_1 } & Distal Intergenic \\
\hline & $\operatorname{chr} 14$ & 19416945 & $5 \quad 19417333$ & 389 & 390 & 19417067 & 548 & 93.27022 & 2.77636 & \multicolumn{2}{|c|}{86.73123 h48q_peak_2 } & Exon (ENSMUST00000177817.1/ENSMUST00000177817.1, exon 3 of 6) \\
\hline & $\operatorname{chr} 15$ & 57420045 & $5 \quad 57420372$ & 328 & 329 & 57420237 & 52 & 27.1149 & 6.42302 & \multicolumn{2}{|c|}{20.97153 h48q_peak_3 } & Intron (ENSMUST00000110196.7/210463, intron 2 of 11) \\
\hline & $\operatorname{chr} 17$ & 70148376 & 670148612 & 237 & 238 & 70148492 & 25 & 15.59956 & 6.57162 & 9.64647 & h48q_peak_4 & Intron (ENSMUST00000133983.7/224997, intron 2 of 13) \\
\hline & $\operatorname{chr} 19$ & 7819353 & 37819604 & 252 & 253 & 7819460 & 8 & 8.44895 & 5.99188 & 2.7315 & h48q_peak_5 & Distal Intergenic \\
\hline & $\operatorname{chr} 2$ & 98666629 & 98667249 & 621 & 622 & 98666699 & 3686 & 109.84236 & 1.47859 & 103.24246 & h48q_peak_6a & Exon (ENSMUST00000099683.1/ENSMUST00000099683.1, exon 1 of 5) \\
\hline & $\operatorname{chr} 2$ & 98666629 & 986667249 & 621 & 622 & 98666955 & 57698 & 434.53357 & 1.74274 & 427.47702 & h48q_peak_6b & Exon (ENSMUST00000099683.1/ENSMUST00000099683.1, exon 1 of 5) \\
\hline & $\operatorname{chr} 2$ & 98666629 & 98667249 & 621 & 622 & 98667144 & $4 \quad 11178$ & 1006.2702 & 2.05435 & 998.4787 & h48q_peak_6c & Exon (ENSMUST00000099683.1/ENSMUST00000099683.1, exon 1 of 5) \\
\hline & $\operatorname{chr} 3$ & 120717119 & 9 120717555 & 437 & 438 & 120717365 & 20 & 15.99121 & 8.02244 & 10.01955 & h48q_peak_7 & Intron (ENSMUST00000182124.7/320739, intron 3 of 11) \\
\hline & chr4 & 43301636 & 643301940 & 305 & 306 & 43301778 & 24 & 11.64038 & 4.92899 & 5.79738 & h48q_peak_8 & Intron (ENSMUST00000056010.12/320571, intron 3 of 14) \\
\hline & chr 4 & 91635805 & 591636087 & 283 & 284 & 91635950 & 17 & 14.71 & 8.08194 & 8.78573 & h48q_peak_9 & Distal Intergenic \\
\hline & chr6 & 16210133 & $3 \quad 16210453$ & 321 & 322 & 16210292 & 11 & 9.33621 & 6.15927 & 3.58403 & 3 h48q_peak_10 & Distal Intergenic \\
\hline & chr8 & 80640572 & 280640923 & 352 & 353 & 80640764 & 57 & 28.57387 & 6.22891 & 22.3752 & h48q_peak_11 & Intron (ENSMUST00000039695.6/333315, intron 2 of 7) \\
\hline & $\operatorname{chr} 9$ & 3000382 & 23000620 & 239 & 240 & 3000558 & 1395 & 24.41663 & 1.33377 & 18.32842 & h48q_peak_12 & Exon (ENSMUST00000181242.1/ENSMUST00000181242.1, exon 4 of 4) \\
\hline & $\operatorname{chr} 9$ & 3000898 & 3001240 & 343 & 344 & 3000965 & 819 & 59.99938 & 1.8797 & 53.58644 & h48q_peak_13 & Exon (ENSMUST00000151376.2/ENSMUST00000151376.2, exon 1 of 4) \\
\hline & $\operatorname{chr} 9$ & 3003379 & 9 3003656 & 278 & 279 & 3003521 & 202 & 35.2648 & 2.75254 & 28.97036 & h48q_peak_14 & Exon (ENSMUST00000177722.7/ENSMUST00000177722.7, exon 1 of 5) \\
\hline & chr9 & 3020248 & $8 \quad 3020540$ & 293 & 294 & 3020426 & 157 & 43.19518 & 3.76697 & 36.8365 & h48q_peak_15 & Exon (ENSMUST00000179272.1/ENSMUST00000179272.1, exon 3 of 5) \\
\hline & $\operatorname{chr} \mathrm{X}$ & 58339146 & 658339440 & 295 & 296 & 58339273 & 13 & 16.02702 & 9.6802 & 10.042 & h48q_peak_16 & Distal Intergenic \\
\hline & $\operatorname{chr} X$ & 59930586 & 659930849 & 264 & 265 & 59930698 & 13 & 10.19175 & 6.28595 & 4.40914 & 4 h48q_peak_17 & Distal Intergenic \\
\hline & $\operatorname{chr} X$ & 106186725 & 5106187108 & 384 & 385 & 106186927 & 162 & 349.90701 & 113.3403 & 342.95636 & h48q_peak_18 & Promoter $(<=1 \mathrm{~kb})$ \\
\hline
\end{tabular}

Advance Publication Journal of Atherosclerosis and Thrombosis Accepted for publication: February 7, 2021 Published online: March 27, 2021 
(Cont. Supplementary Table 2)

\begin{tabular}{|c|c|c|c|c|c|c|c|c|c|c|}
\hline \multirow{3}{*}{$\begin{array}{c}\text { gene } \\
\text { Chr }\end{array}$} & \multirow{3}{*}{$\begin{array}{r}\text { gene Start } \\
91806043\end{array}$} & \multirow{3}{*}{$\begin{array}{r}\text { gene End } \\
91849157\end{array}$} & \multirow{3}{*}{$\begin{array}{l}\begin{array}{l}\text { gene } \\
\text { Length }\end{array} \\
43115\end{array}$} & \multirow{2}{*}{\multicolumn{2}{|c|}{$\begin{array}{l}\text { gene } \\
\text { Strand geneId }\end{array}$}} & \multirow{3}{*}{$\begin{array}{l}\text { transcriptld } \\
\text { ENSMUST00000178462.7 }\end{array}$} & \multicolumn{2}{|l|}{ distance } & \multirow[b]{2}{*}{ SYMBOL } & \multirow[b]{2}{*}{ GENENAME } \\
\hline & & & & & & & ToTSS & ENSEMBL & & \\
\hline & & & & 2 & 20338 & & -322417 & ENSMUSG00000020964 & Sell1 & sel-1 suppressor of lin-12-like (C. elegans) \\
\hline 13 & 96388294 & $4 \quad 96417737$ & 29444 & 1 & 67463 & ENSMUST00000099295.5 & -28335 & ENSMUSG00000021671 & Poc5 & POC5 centriolar protein \\
\hline 14 & 19594139 & 19602581 & 8443 & 2 & 432825 & ENSMUST00000096121.11 & 185301 & ENSMUSG00000095024 & $\mathrm{Gm} 5458$ & predicted gene 5458 \\
\hline 3 & 120772730 & 120886691 & 113962 & 2 & 320739 & ENSMUST00000182099.1 & 169195 & NA & 6530403H02Rik & RIKEN cDNA $6530403 \mathrm{H} 02$ gene \\
\hline 4 & 43267191 & 143326560 & 59370 & 1 & 320571 & ENSMUST00000102953.3 & 34408 & ENSMUSG00000028457 & Atp8b5 & ATPase, class I, type 8B, member 5 \\
\hline 5 & 102907950 & 103100081 & 192132 & 2 & 26414 & ENSMUST00000112848.7 & -28675 & ENSMUSG00000046709 & Mapk10 & mitogen-activated protein kinase 10 \\
\hline 8 & 80611080 & 80695356 & 84277 & 1 & 333315 & ENSMUST00000039695.6 & 29522 & ENSMUSG00000042353 & Frem3 & Fras1 related extracellular matrix protein 3 \\
\hline 8 & 81342556 & $6 \quad 81745902$ & 403347 & 1 & 234515 & ENSMUST00000172167.8 & -19074 & ENSMUSG00000037940 & Inppab & inositol polyphosphate-4-phosphatase, type II \\
\hline 12 & 91806043 & 91849157 & 43115 & 2 & 20338 & ENSMUST00000178462.7 & -322436 & ENSMUSG00000020964 & Sell & sel-1 suppressor of lin-12-like (C. elegans) \\
\hline 13 & 96388294 & 96417737 & 29444 & 1 & 67463 & ENSMUST00000099295.5 & -28313 & ENSMUSG00000021671 & Poc5 & POC5 centriolar protein \\
\hline 14 & 19594139 & 19602581 & 8443 & 2 & 432825 & ENSMUST00000096121.11 & 185307 & ENSMUSG00000095024 & Gm5458 & predicted gene 5458 \\
\hline 15 & 57243771 & 57477625 & 233855 & 2 & 210463 & ENSMUST00000110196.7 & 57294 & ENSMUSG00000022366 & Slc22a22 & solute carrier family 22 (organic cation transporter), member 22 \\
\hline 2 & 97468089 & 97629063 & 160975 & 1 & 241568 & ENSMUST00000170144.1 & 1198786 & ENSMUSG00000050587 & Lrrc4c & leucine rich repeat containing $4 \mathrm{C}$ \\
\hline 3 & 120772730 & 120886691 & 113962 & 2 & 320739 & ENSMUST00000182099.1 & 169189 & NA & 6530403H02Rik & RIKEN cDNA $6530403 \mathrm{H} 02$ gene \\
\hline 4 & 43267191 & 43326560 & 59370 & 1 & 320571 & ENSMUST00000102953.3 & 34419 & ENSMUSG00000028457 & Atp8b5 & ATPase, class I, type 8B, member 5 \\
\hline 8 & 19729576 & 19753527 & 23952 & 1 & 626415 & ENSMUST00000098909.4 & 32818 & ENSMUSG00000096265 & 4930467E23Rik & RIKEN cDNA 4930467E23 gene \\
\hline 8 & 80611080 & 80695356 & 84277 & 1 & 333315 & ENSMUST00000039695.6 & 29500 & ENSMUSG00000042353 & Frem3 & Fras1 related extracellular matrix protein 3 \\
\hline $\mathrm{x}$ & 106187100 & 106203699 & 16600 & 1 & 18655 & ENSMUST00000081593.12 & 0 & ENSMUSG00000062070 & Pgkl & phosphoglycerate kinase 1 \\
\hline 13 & 96388294 & 96417737 & 29444 & 1 & 67463 & ENSMUST00000099295.5 & -28322 & ENSMUSG00000021671 & Poc5 & POC5 centriolar protein \\
\hline 14 & 19594139 & 19602581 & 8443 & 2 & 432825 & ENSMUST00000096121.11 & 185248 & ENSMUSG00000095024 & Gm5458 & predicted gene 5458 \\
\hline 15 & 57243771 & 57477625 & 233855 & 2 & 210463 & ENSMUST00000110196.7 & 57253 & ENSMUSG00000022366 & Slc22a22 & solute carrier family 22 (organic cation transporter), member 22 \\
\hline 17 & 69969421 & 70594408 & 624988 & 1 & 224997 & ENSMUST00000130971.1 & 178955 & ENSMUSG00000003279 & Dlgap1 & DLG associated protein 1 \\
\hline 19 & 7781980 & 7802667 & 20688 & 2 & 236149 & ENSMUST00000065634.7 & -16686 & ENSMUSG00000053303 & Slc22a26 & solute carrier family 22 (organic cation transporter), member 26 \\
\hline 2 & 97468089 & 97629063 & 160975 & 1 & 241568 & ENSMUST00000170144.1 & 1198540 & ENSMUSG00000050587 & Lrrc4c & leucine rich repeat containing $4 \mathrm{C}$ \\
\hline 2 & 97468089 & 97629063 & 160975 & 1 & 241568 & ENSMUST00000170144.1 & 1198540 & ENSMUSG00000050587 & Lrrc4c & leucine rich repeat containing $4 \mathrm{C}$ \\
\hline 2 & 97468089 & 97629063 & 160975 & 1 & 241568 & ENSMUST00000170144.1 & 1198540 & ENSMUSG00000050587 & Lrrc4c & leucine rich repeat containing $4 \mathrm{C}$ \\
\hline 3 & 120772730 & 120886691 & 113962 & 2 & 320739 & ENSMUST00000182099.1 & 169136 & NA & 6530403H02Rik & RIKEN cDNA $6530403 \mathrm{H} 02$ gene \\
\hline 4 & 43267191 & 43326560 & 59370 & 1 & 320571 & ENSMUST00000102953.3 & 34445 & ENSMUSG00000028457 & Atp8b5 & ATPase, class I, type 8B, member 5 \\
\hline 4 & 91250763 & 91399984 & 149222 & 2 & 15569 & ENSMUST00000102799.9 & -235821 & ENSMUSG00000008489 & Elav12 & ELAV like RNA binding protein 1 \\
\hline 6 & 15727799 & 15770349 & 42551 & 1 & 16543 & ENSMUST00000128849.2 & 482334 & ENSMUSG00000041390 & Mdfic & MyoD family inhibitor domain containing \\
\hline 8 & 80611080 & 80695356 & 84277 & 1 & 333315 & ENSMUST00000039695.6 & 29492 & ENSMUSG00000042353 & Frem3 & Fras1 related extracellular matrix protein 3 \\
\hline 9 & 3038669 & 3038743 & 75 & 2 & 100628572 & ENSMUST00000195989.1 & 38123 & ENSMUSG00000106183 & Mir101c & microRNA 101c \\
\hline 9 & 3038669 & 3038743 & 75 & 2 & 100628572 & ENSMUST00000195989.1 & 37503 & ENSMUSG00000106183 & Mir101c & microRNA 101c \\
\hline 9 & 3038669 & 3038743 & 75 & 2 & 100628572 & ENSMUST00000195989.1 & 35087 & ENSMUSG00000106183 & Mir101c & microRNA 101c \\
\hline 9 & 3038669 & 3038743 & 75 & 2 & 100628572 & ENSMUST00000195989.1 & 18203 & ENSMUSG00000106183 & Mir101c & microRNA 101c \\
\hline $\mathrm{X}$ & 58031010 & 58041736 & 10727 & 1 & 22773 & ENSMUST00000088629.3 & 308136 & ENSMUSG00000067860 & Zic3 & zinc finger protein of the cerebellum 3 \\
\hline $\mathrm{x}$ & 59999464 & 60030759 & 31296 & 1 & 14071 & ENSMUST00000033477.4 & -68615 & ENSMUSG00000031138 & F9 & coagulation factor IX \\
\hline $\mathrm{X}$ & 106187100 & 106203699 & 16600 & 1 & 18655 & ENSMUST00000081593.12 & 0 & ENSMUSG00000062070 & Pgkl & phosphoglycerate kinase 1 \\
\hline
\end{tabular}

Advance Publication Journal of Atherosclerosis and Thrombosis 

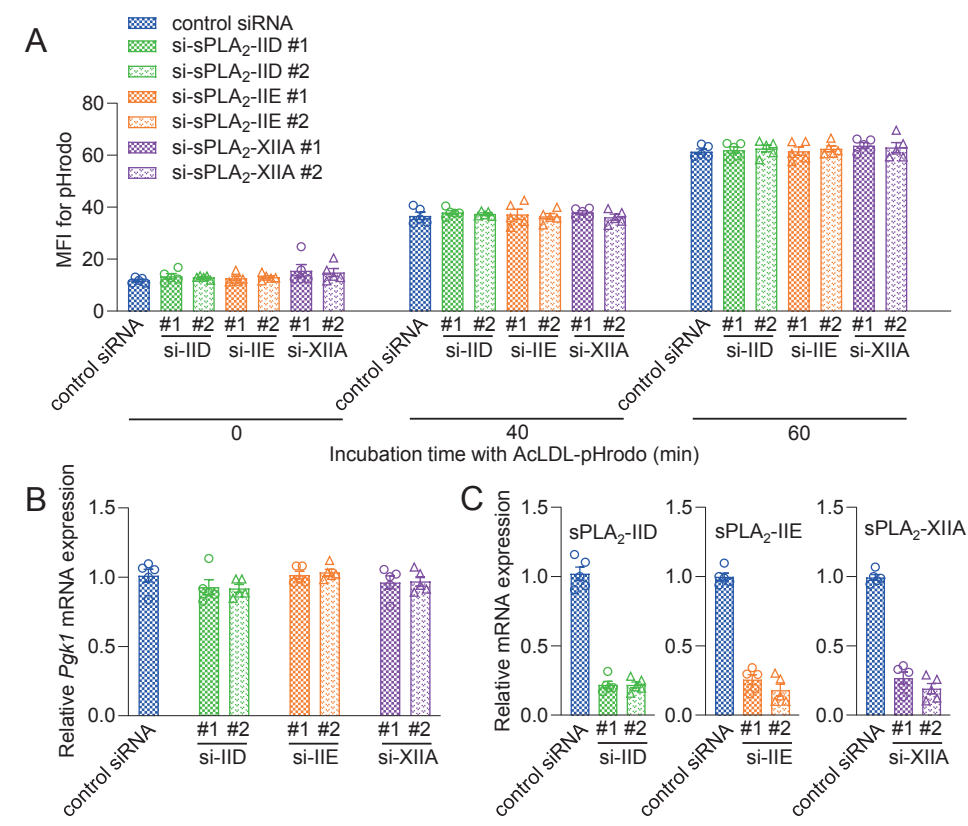

Supplementary Fig.2. Effects of siRNA-mediated knockdown of sPLA2-IID, -IIE, or -XIIA on Intracellular Translocation of AcLDL to Lysosomes and PGK1 Expression in sPLA2-V WT RAW264.7 Cells

$A$ and $B$, siRNA-mediated reduction of expression of sPLA2-IID, -IIE, or -XIIA did not change translocation of pHrodo-conjugated AcLDL to lysosomes (A) and expression of Pgk1 mRNA at baseline (B). MFI indicates mean fluorescence intensity. $n=5$ in each experiment. Values in $\mathrm{B}$ were normalized to that of control siRNA $(=1)$. C, Reduction of expression of sPLA2-IID, -IIE, or -XIIA mRNA by their respective siRNAs (\#1 and \#2). $n=5$ in each experiment. Values were normalized to that of control siRNA $(=1)$. 